Research paper

\title{
Hierarchical-microstructure based modeling for plastic deformation of partial recrystallized copper
}

\author{
Yao Liu ${ }^{\mathrm{a}}$, Songlin Cai ${ }^{\mathrm{b}, *}$, Mingyao Su ${ }^{\mathrm{c}, \mathrm{d}}$, Yunjiang Wang ${ }^{\mathrm{c}, \mathrm{d}}$, Lanhong Dai ${ }^{\mathrm{c}, \mathrm{d}, *}$ \\ ${ }^{a}$ School of Mathematics and Physics, University of Science and Technology Beijing, Beijing 100083, PR China \\ ${ }^{\mathrm{b}}$ China Electric Power Research Institute, Beijing 100192, PR China \\ ' State Key Laboratory of Nonlinear Mechanics, Institute of Mechanics, Chinese Academy of Sciences, Beijing 100190, PR China \\ ${ }^{\mathrm{d}}$ School of Engineering Science, University of Chinese Academy of Sciences, Beijing 101408, PR China
}

\section{A R T I C L E I N F O}

\section{Keywords:}

Hierarchical microstructure

Yield function

Partial recrystallization

Metallic material

Mechanical property

\begin{abstract}
A B S T R A C T
Hierarchical microstructure in partial recrystallized materials can simultaneously improve the strength and ductility of metallic materials. Modeling the mechanical behavior of partial recrystallized materials helps to process materials with superior combination of ductility and strength. Here, using experimental characterization, cellular automation (CA) and finite element method, hierarchical-microstructure based modeling was proposed to simulate the tensile deformation of partial recrystallized copper. Firstly, partial recrystallized coppers with different volume fractions of recrystallization were produced by means of extrusion machining and subsequent heat treatment (HT). Uniaxial tensile tests and microstructural observations show that the hierarchical-microstructure of recrystallized grains (RGs) surrounded by elongated subgrains has a significant effect on the mechanical properties. Then, based on the experimental results, a hierarchical-microstructure based plasticity model was developed to describe the yield surface of partial recrystallized materials. CA was further employed to simulate the hierarchical microstructure. By embedding the plasticity model and simulated hierarchical-microstructure in finite element method, a finite element model (FEM) for mechanical behavior of partial recrystallized copper was proposed, where the elongated subgrain with forest dislocation and low angle grain boundary, the RG with few dislocations and twin boundary, and volume fraction of recrystallization were taken into consideration. Finally, the experimental data and the comparison with the conventional plasticity model validate the rationality of the proposed model.
\end{abstract}

\section{Introduction}

For metallic materials in many applications, there is significant interest in enhancing strength in balance with good ductility (Meyers and Chawla, 2009; Ming et al., 2018; Valiev et al., 2016). Extensive investigations have proved that superior combination of ductility and strength is able to be achieved by combining severe plastic deformation (SPD) technology with heat treatment (HT) (Ma and Zhu, 2017; Ovid'ko et al., 2018). Bimodal copper produced by cryogenic rolling and subsequent annealing possesses superior balance between strength and ductility (Wang et al., 2002). Nanostructured copper could combine high strength and good ductility by inducing static recrystallization during annealing process (Li et al., 2008b; Zhang et al., 2008). Dynamic plastic deformation and subsequent thermal annealing were employed to produce good-ductility and high-strength $\mathrm{Cu}-\mathrm{Zn}$ alloy by mixing nanotwin bundles with microsized recrystallized grains
(Xiao et al., 2011). Asymmetric rolling and partial recrystallization were conducted to fabricate heterogeneous lamella structural titanium with high-strength and coarse-grain-ductility (Wu et al., 2015). Rapid annealing treatment after high pressure torsion was used to achieve full recrystallization in ultrafine grains, resulting in improvement of both strength and ductility (Zheng et al., 2017). To-date, the trade-off of strength and ductility has been overcome in various metallic materials by combining SPD and subsequent HT: (i) the conventional metals, including copper (Tian et al., 2018), stainless steel (El-Tahawy et al., 2018; Sun et al., 2019) and titanium (Huang et al., 2019); (ii) the new class of materials, including medium-entropy (Laplanche et al., 2017) alloy and high-entropy alloy (Sun et al., 2018; Wu et al., 2019).

Modeling the deformation behavior of materials processed by SPD and HT is an important research area, which helps to optimize the processing parameters for enhancement of both strength and ductility. For metallic materials, the elastic deformation is linear and obeys

\footnotetext{
* Corresponding authors.

E-mail addresses: caisonglin@lnm.imech.ac.cn (S. Cai), lhdai@lnm.imech.ac.cn (L. Dai).
} 


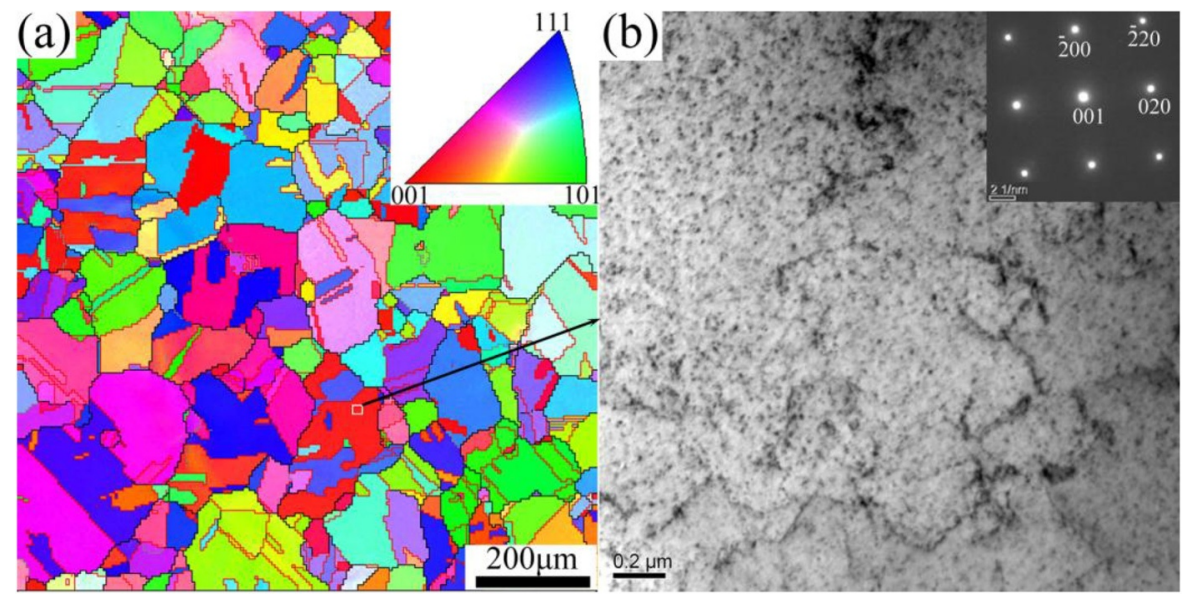

Fig. 1. Microstructures of initial copper workpiece: (a) Orientation imaging map (OIM) along normal direction (ND); (b) TEM micrograph in the local zone of (a).

Hooke's law (Hooke, 1678). Plastic deformation often stems from nonlinear processes like dislocation, void, slip, twinning, necking, shear banding, crack etc.; therefore, plentiful models for plastic deformation have been proposed for different considerations. Hill (1948) put forward a quadratic yield criterion to predict the plastic deformation of isotropic hardening. Hosford (1979) introduced a yield criterion to characterize yielding behavior of materials subjected to plane stress. In the condition of finite strains, Loret (1983) established constitutive equations for anisotropic materials. Barlat et al. (1991) developed a yield function with six independent components for anisotropic materials by means of two linear transformations of the stress tensor. Karafillis and Boyce (1993) further generalized linear transformation to develop the yield function for both isotropic and anisotropic materials. Considering the dependence of strain rate and temperature, NematNasser et al. (1998) proposed a constitutive model for face-centered cubic (FCC) single crystals. Zikry and Kameda (1998) put forward a dislocation-density based constitutive framework to understand the deformation mechanisms of intermetallics at high strain rate. Because the macrostrain has an effect on the macrostress in nature, Hori and Nemat-Nasser (1999) advised a hybird micromechanics model for heterogeneous materials. In order to model deformation of heterogeneous nanograined materials, Altan and Subhash (2003) presented the representative volume element with two isotropic material properties. A gradient plasticity model was introduced to characterize the deformation patterns of slip lines and slip bands (Tsagrakis et al., 2006; Zaiser and Aifantis, 2006). A theory of dynamic recrystallization softening was suggested to model the formation of shear bands (Osovski et al., 2013; Rittel et al., 2008, 2006). Srivastava and NematNasser (2011) presented universal theorems to formulate the dynamic behavior of linearly elastic heterogeneous solid. The homogenous anisotropic hardening model was developed for the description of the strain hardening response of metallic materials under non-proportional loading (Barlat et al., 2014; Ha et al., 2013). By coupling plasticity to martensitic phase transformation, Sadjadpour et al. (2015) extended a thermo-mechanical model to investigate the dynamic shear deformation. Recently, by means of a self-consistent method, AbdulLatif et al. (2018) developed a model to describe the mechanical response of heterogeneous ultrafine grained and nanocrystalline FCC metals. Ziaei and Zikry (2019) understood the aggregate behavior of multi-phase crystalline by combining microstructural interactions with the dislocation-density framework. Considering the effect of transient mobile dislocation density, Varma et al. (2019) provided a stress relaxation constitutive model to predict strain hardening rate. Moreover, some microstructural observations were carried out on the materials processed by SPD and HT to analyze the mechanism of plastic deformation (Ma and Zhu, 2017; Ovid'ko et al., 2018; Tian et al., 2018; Zheng et al., 2017). The experimental results show that the hierarchical-microstructure with the heterogeneous grains separated and surrounded by nanostructures can be created in partial recrystallized materials. These results inspired us to develop a hierarchical-microstructure based plasticity model for the description of mechanical behavior in partial recrystallized materials.

In present work, a theoretical model is proposed to characterize the mechanical behavior of partial recrystallized cooper with hierarchicalmicrostructure. Partial recrystallized coppers were processed using a SPD method of extrusion machining and subsequent HT at different temperatures. Based on tensile tests and microstructural observations, we investigated the relationship between microstructure and mechanical property. After analyzing the experimental results, a theoretical model combining cellular automation (CA) and finite element method was proposed to describe the mechanical response of partial recrystallized cooper. The accuracy and rationality of the proposed model were further discussed.

\section{Experiments}

\subsection{Experimental procedure}

Fig. 1 illustrates the initial microstructure of copper with the composition (wt\%): $\mathrm{Cu}(99.95 \%), \mathrm{Fe}(0.004 \%), \mathrm{S}(0.004 \%), \mathrm{Pb}(0.003 \%)$, Zn $(0.003 \%)$, Sn $(0.002 \%)$. The initial copper possesses coarse grain face center cubic (FCC) microstructure and the average grain size is $\sim 100 \mu \mathrm{m}$. The initial copper was first processed at the shear strain of 3.1 by using the SPD method of quasi-static extrusion machining (QSEM) (Liu et al., 2019), and then the SPDed copper was annealed for $5 \mathrm{~min}$ at the temperatures of $293,473,523,548,573,773 \mathrm{~K}$. After QSEM and subsequent HT, copper with a gauge dimension of $12 \times 2.5 \times 0.5 \mathrm{~mm}^{3}$ was tested by means of Instron E10000. All uniaxial tensile tests were conducted at the same strain rate $\left(2.5 \times 10^{-4} \mathrm{~s}^{-1}\right)$. Copper annealed at each temperature was tested at least 3 times. Electron backscatter diffraction (EBSD) at the scanning step length of $0.5 \mu \mathrm{m}$ was conducted on JOEL JSM-7800F. Transmission electron microscope (TEM) test at $200 \mathrm{kV}$ operating voltage was performed on JEM 2010.

\subsection{Mechanical property}

The tensile test results were shown in Fig. 2. As for initial copper, the $0.2 \%$ yield strength is $\sim 47 \mathrm{MPa}$, the ultimate tensile strength is $\sim 196 \mathrm{MPa}$, and the uniform elongation is $\sim 41.7 \%$. SPDed copper annealed at low temperature possesses improved strength but poor uniform elongation. High ductility but low strength can be achieved if SPDed copper is annealed at high temperature. As illustrated in Fig. 2b, $523 \mathrm{~K}$ is the transition temperature of HT. SPDed copper annealed 

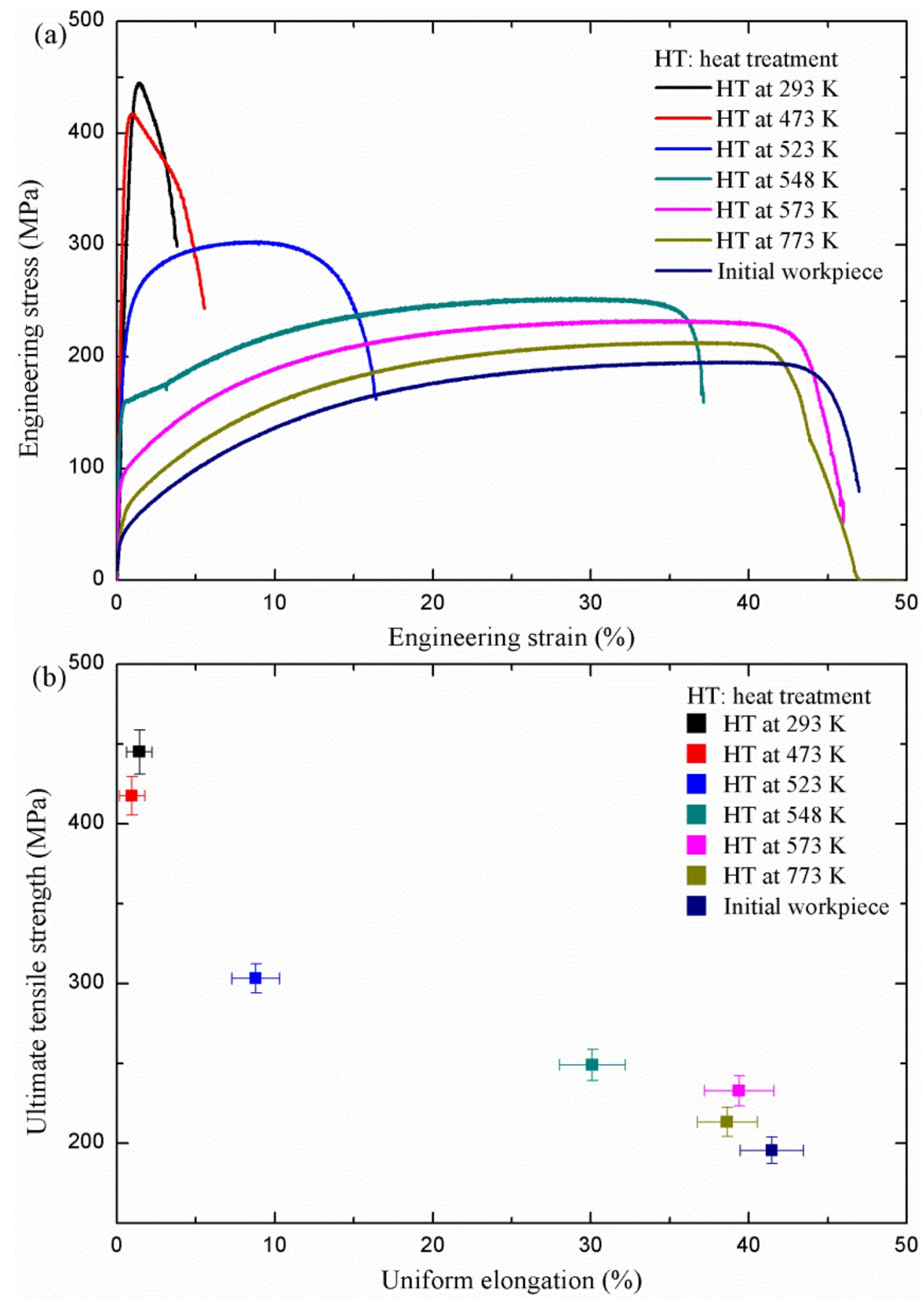

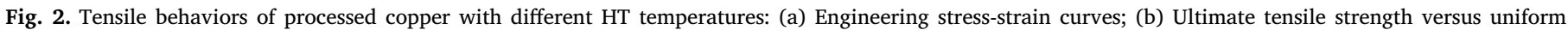
elongation.

below $523 \mathrm{~K}$ possesses high strength but low ductility; otherwise, copper has low strength but high ductility. In particular, compared with the initial workpiece, SPDed copper annealed at $573 \mathrm{~K}$ has doubled yield strength but no reduction in ductility.

\subsection{Microstructural observations}

Fig. 3 shows the distribution of grain boundary misorientation which contains low angle grain boundary (LAGB) and high angle grain boundary (HAGB). According to Fig. 3a, a mass of LAGBs but few twin boundaries (TBs) appear in SPDed copper annealed at $293 \mathrm{~K}$. LAGB resulting from forest dislocation helps to improve the strength. As for high HT temperature (Fig. 3c-d), the frequency of $\sim 60^{\circ}$ misorientation angle is relatively high, which indicates the formation of $\Sigma 3$ twin boundaries (TBs). $\Sigma 3$ twin boundaries are coherent interfaces providing a possible slip transfer (Christian and Mahajan, 1995; Lu et al., 2009), which could obstruct the motion of dislocations and accommodate some dislocations.

Fig. 4 shows EBSD image quality map of SPDed copper annealed at different temperatures. SPDed copper annealed at $293 \mathrm{~K}$ (Fig. 4a) is filled with severe-plastic-deformed (SPDed) grains which contain a mass of LAGBs. If the HT temperature is greater than or equal to $523 \mathrm{~K}$ (Fig. 4b-d), there are two types of grains in copper sheet, i.e., SPDed grains and recrystallized grains (RGs). It is illustrated in Fig. 4 that the volume fraction of RG is larger at higher HT temperature.

Fig. 5 shows the TEM observation of SPDed copper annealed at 

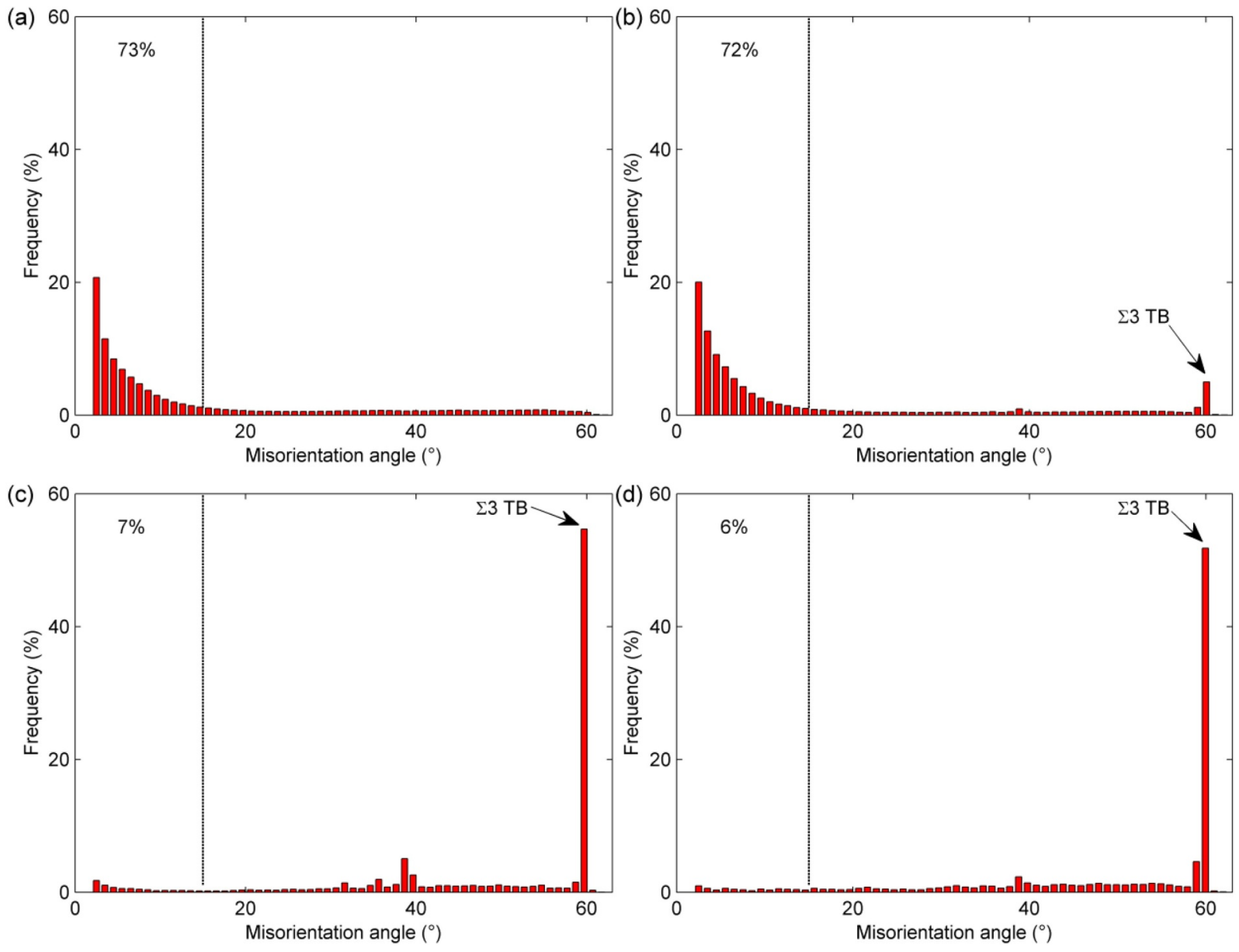

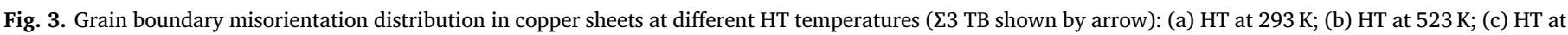
$573 \mathrm{~K}$; (d) HT at $773 \mathrm{~K}$.

$523 \mathrm{~K}$. RGs are surrounded by SPDed grains. The average grain size of RG is $\sim 4 \mu \mathrm{m}$ (Fig. 5a). SPDed grains are elongated subgrains which are full of forest dislocations (Fig. 5b). The capacity to store new dislocation is poor in SPDed grains. SPDed grains possess high strength but poor ductility. Comparing Fig. $5 \mathrm{~b}$ and c, fewer dislocations appear within RG. New dislocations could be stored in RGs during plastic deformation, which helps to the improvement of ductility.

Orientation imaging maps (OIMs) for processed coppers are illustrated in Fig. 6. Compared with initial copper (Fig. 1a), SPDed grains tend to rotate toward the texture component $\{111\}$ in SPDed copper (Fig. 6a). If subsequent HT is conducted in SPDed grains, small RGs emerge with the random orientations (Fig. 6b-d). The pole figures of processed copper at different HT temperatures are plotted in Fig. 7 to further reveal the random orientation of RGs. As shown in Fig. 7a, the processed copper without RGs possesses strong basal texture $(\{100\}|| N D)$. As for partial recrystallized copper in Fig. 7b, RGs with random orientation weaken the basal texture $(\{100\}|| N D)$. The basal texture becomes weaker with the increasing HT temperature (Fig. 7c). When HT temperature is higher than $573 \mathrm{~K}$, full recrystallization happens in copper. The randomization of the texture is observed in full recrystallized copper (Fig. 7d), which indicates that RG texture is nearly random.

It is illustrated in Figs. 3-7 that partial recrystallization happens during subsequent HT of SPDed copper. A hierarchical microstructure, i.e., small RGs surrounded by SPDed grains, can be produced in partial recrystallized copper. According to Hall-Petch relationship (Hall, 1951; Petch, 1953), small RGs can improve the strength of material. There is a difference of texture component between SPDed grain and RG, which could have an inevitable effect on the mechanical behavior. SPDed grains saturated with forest dislocation improve strength. RGs with few dislocations and coherent TBs inside help to the improvement of ductility. High strength and high ductility of partial recrystallized copper attribute to the hierarchical microstructure.

\section{Model for partial recrystallized copper}

Partial recrystallized copper possesses hierarchical microstructure; therefore, the conventional plasticity model only for SPDed grains or RGs is not suitable for mechanical behavior of partial recrystallized copper. A new plasticity model considering the hierarchical-microstructure is needed to characterize the plastic deformation of partial recrystallized copper.

\subsection{Cellular automaton simulation}

Cellular automation (CA) has been widely employed to simulate microstructural evolutions, e.g., solidification (Chen et al., 2015), phase transition (Bussemaker et al., 1997), grain growth (Davies, 1997; Gandin and Rappaz, 1997), static recrystallization (Kühbach et al., 2016; Marx et al., 1999), and dynamic recrystallization (Chen et al., 2010; Popova et al., 2015). The detailed theory for CA has been described in the literatures (Chen et al., 2009; Ding and Guo, 2001). Here, the algorithm of CA is directly used to simulate the hierarchical-microstructure of partial recrystallized copper. A two-dimensional CA model was employed. The 2-D CA model is composed of $200 \times 200$ equal-sized square cells. Four typical state transformation rules were employed. As shown in Fig. 8, an arbitrary site is determined by its neighbouring sites. 


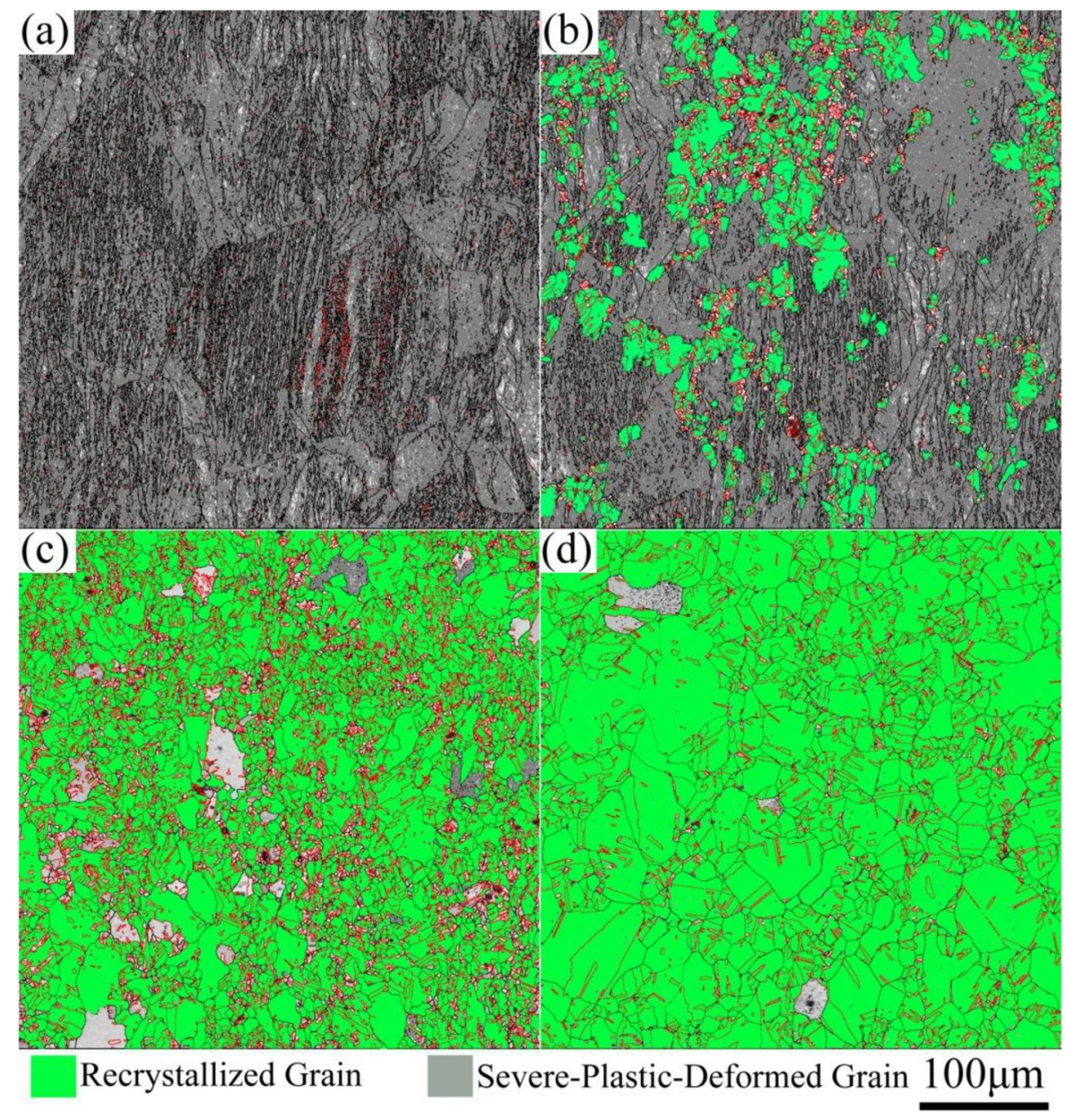

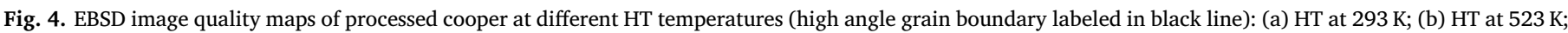
(c) HT at $573 \mathrm{~K}$; (d) HT at $773 \mathrm{~K}$

Rule 1: the orientation in cell C5 depends on both nearest (C2, C4, C6 and C8) and next-nearest (C1, C3, C7 and C9) neighbors. The state of cell $\mathrm{C} 5$ could transform to the state $\mathrm{S}$ in the next cellular automaton step if the number of its neighboring cells with state $S$ is not less than five.

Rule 2: the orientation in cell $\mathrm{C5}$ is determined by its nearest neighbors (C2, C4, C6 and C8). The state of cell C5 could transform to the state $\mathrm{S}$ in the next cellular automaton step if arbitrary three of the cells C2, C4, C6 and C8 possesses the state S.

Rule 3: the orientation in cell C5 is related with its next-nearest neighbors (C1, C3, C7 and C9). The state of cell C5 could transform to the state $S$ in the next cellular automaton step if arbitrary three of the cells C1, C3, C7 and C9 possesses the state S.

Rule 4: if none of the above rules $1-3$ is satisfied, the state of cell C5 could randomly transform to an arbitrary state of its nearest (C2, C4, C6 and $\mathrm{C} 8$ ) and next-nearest (C1, C3, C7 and C9) neighbors.

The probability of cell C5 state transition relies on the change of interfacial energy between before and after the trial transition. The state transition happens if the total interfacial energy decreases after the trial transition. The lowest energy principle (Chen et al., 2010; He et al., 2006) is used to characterize the normal grain growth:

$P=\left\{\begin{array}{l}1, \Delta E_{i, j}<0 \\ 0, \Delta E_{i, j} \geq 0\end{array}\right.$

$E_{i}=\gamma \sum_{k}^{c}\left(1-\delta_{C_{i} C_{k}}\right)$

$\Delta E_{i, j}=E_{j}-E_{i}$
In Eqs. (1)-(3), $\gamma$ is grain boundary energy, $\delta$ is Kronecker symbol, $k$ is the $k$ th neighbor to site $i$, and $c$ is the total number of site $i . C_{i}$ and $C_{k}$ are respectively the orientations of site $i$ and $k$. Site $j$ or $k$ refers to one of the nearest ( $\mathrm{C} 2, \mathrm{C} 4, \mathrm{C} 6$ and $\mathrm{C} 8$ ) and next-nearest (C1, C3, C7 and C9) neighbors. $P$ is the transition probability controlling the state of cell $\mathrm{C} 5$.

The nucleation and growth of recrystallization in CA are modeled by the following expressions (Ding and Guo, 2001):

$\dot{n}(\dot{\varepsilon}, T)=C_{n} \dot{\varepsilon} \exp \left(-\frac{Q_{a c t}}{R T}\right)$

$v_{i}=\frac{h D_{b} b F_{i}}{4 \pi r_{i}^{2} K T} \exp \left(-\frac{Q_{b}}{R T}\right)$

Here, $\dot{n}(\dot{\varepsilon}, T)$ is the nucleation rate of per unit grain boundary area, $\dot{\varepsilon}$ is strain rate, $Q_{a c t}$ is activation energy, $R$ is gas constant, and $T$ is absolute temperature. In Eq. (5), $h$ is characteristic grain boundary thickness, $D_{b}$ is boundary self-diffusion coefficient, $Q_{b}$ is boundary diffusion activation energy, $K$ is Boltzmann's constant, $b$ is Burger's vector, $r_{i}$ is the radius of RG, and $v_{i}$ is the growth velocity of the $i$ th RG. The driving force $F_{i}$ is related with the dislocation density and radius of the ith RG.

In this work, the values of the parameters in Eqs. (1)-(5) can refer to the references (Chen et al., 2010; Ding and Guo, 2001; He et al., 2006). The simulated mean RG size is $4 \mu \mathrm{m}$ obtained from TEM observations in Fig. 5a, and then $r_{i}$ is equal to $2 \mu \mathrm{m}$. Based on the experiments in Fig. $4 \mathrm{~b}$, the nucleation site of recrystallization can be on grain boundary or within SPDed grain. By means of MATLAB-R2009b, the simulated hierarchical-microstructure at the RG volume fraction of $30 \%$ is 

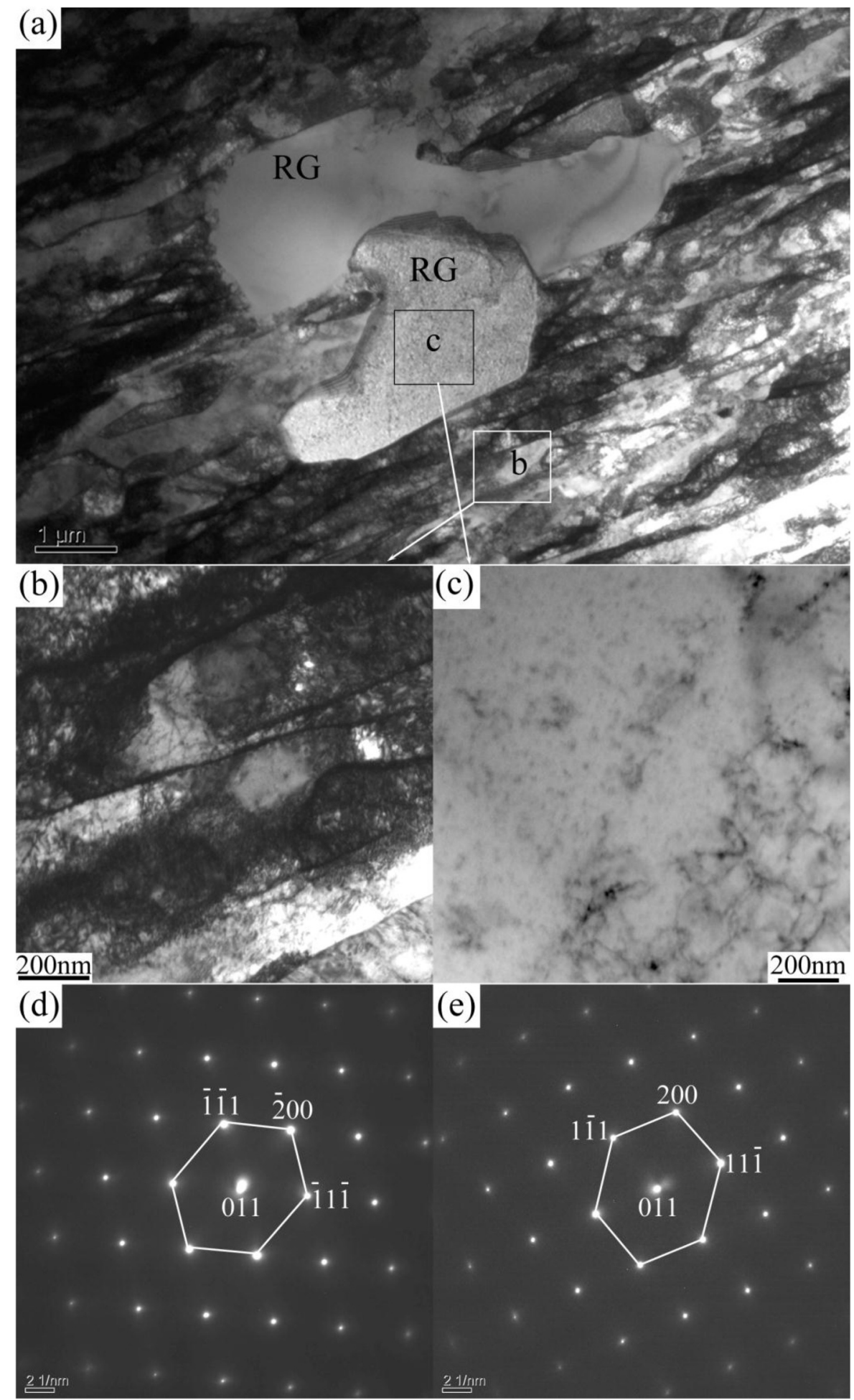

Fig. 5. TEM micrographs of partial recrystallized copper: (a) Recrystallized grains (RGs) are surrounded by elongated subgrains; (b) local magnification of subgrain; (c) local magnification of recrystallized grain; (d)-(e) are the selected area diffraction patterns (SADPs) of (b)-(c) respectively.

illustrated in Fig. 9.

\subsection{Multiple microstructures}

In order to calculate the mechanical response of partial recrystallized copper, the hierarchical-microstructure simulated by CA is combined with finite element method. Using the commercial ABAQUS/ Explicit software (ABAQUS 6.11-1), a 2-D finite element model (FEM) with $200 \times 200$ random elements was set up for uniaxial tension. Based on the experimental measurements (Kumar et al., 2019), the following boundary conditions are used in the proposed FEM. The displacement along $\mathrm{x}$ direction at the top boundary is the same as that at the bottom boundary. Nodes can be free to move along y axe at both the top and bottom boundaries. Displacement along $\mathrm{x}$ direction is fixed in the left side. Displacement in the right side increases linearly at a specific loading speed. Every element in FEM corresponds to one of $200 \times 200$ 


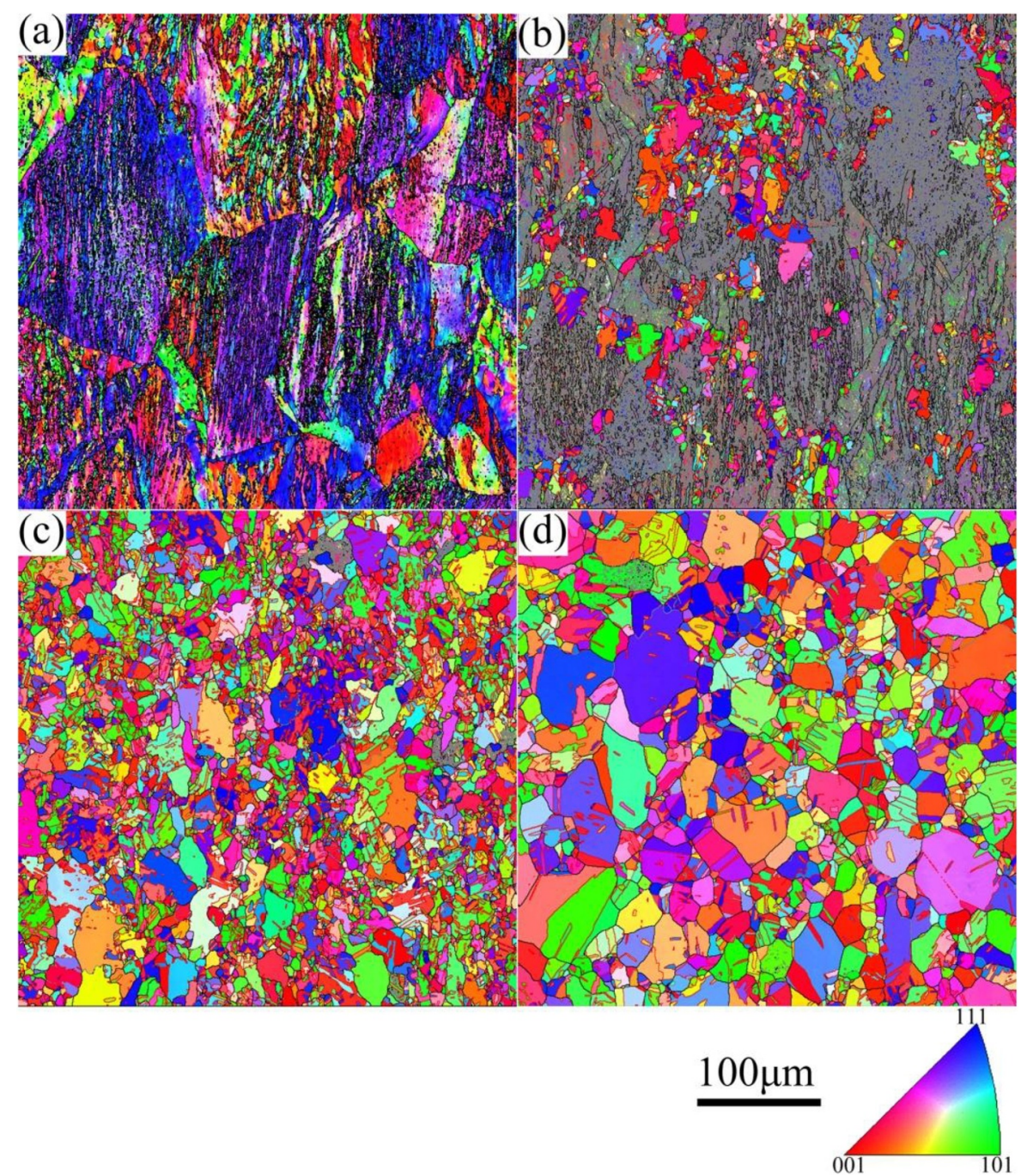

Fig. 6. Orientation imaging maps (OIMs) for processed copper at different HT temperatures (high angle grain boundary labeled in black line): (a) HT at $293 \mathrm{~K}$; (b) HT at $523 \mathrm{~K}$; (c) HT at $573 \mathrm{~K}$; (d) HT at $773 \mathrm{~K}$.

equi-sized square cells in CA, i.e., an element belongs to either SPDed grain or RG. The element size was $1 \times 1 \mu \mathrm{m}$ after mesh sensitivity tests. Two user material subroutines were needed for partial recrystallized copper. One is for SPDed grain and the other is for RG.

Volume fraction of recrystallization can be calculated by using the following equation (Avrami, 1939):

$X=1-\exp \left(-B t^{n}\right)$

where $X$ is volume fraction, $t$ is HT time, $B$ and $n$ are recrystallization kinetic parameters. $B$ is related to the HT temperature. The relationship between $B$ and HT temperature has been put forward in the literature (Liu et al., 2019). Using the results from Liu et al. (2019), the RG volume fraction at different HT temperatures can be given. The RG volume fraction at the HT temperature of $293 \mathrm{~K}, 473 \mathrm{~K}, 523 \mathrm{~K}, 548 \mathrm{~K}$, $573 \mathrm{~K}$ and $773 \mathrm{~K}$ is $0 \%, 11 \%, 37 \%, 57 \%, 76 \%$ and $100 \%$ respectively. Combining RG volume fraction and CA method, the multi-microstructures at different HT temperatures were illustrated in Fig. 10. Fig. 10a is full of SPDed grains. Fig. 10f is filled with RGs. The RG volume fraction increases from Fig. 10b to e.

\subsection{Constitutive model}

The mechanical behaviors of SPDed grains and RGs are assumed to be isotropic. The deformation of partial recrystallized copper is elastoplastic. The deformation gradient tensor $\mathbf{F}$ can be split into two parts, i.e., an elastic part $\mathbf{F}_{\mathbf{e}}$ and a plastic part $\mathbf{F}_{\mathbf{p}}$ (Lee, 1969):.

$\mathbf{F}=\mathbf{F}_{\mathbf{e}} \cdot \mathbf{F}_{\mathbf{p}}$

For elastic deformation in the current configuration, the relationship between Cauchy stress tensor $\boldsymbol{\sigma}$ and the logarithmic elastic strain is linear:

$\sigma=\frac{1}{2} J^{-1} C: \ln \mathbf{b}_{\mathbf{e}}$

where $\mathbf{b}_{\mathbf{e}}$ is elastic Finger tensor and $J$ is the determinant of deformation gradient tensor $\mathbf{F}$. The elastic stiffness $C$ is in the following form:

$C=K \mathbf{I} \otimes \mathbf{I}+2 G\left(\mathrm{I}^{s}-\frac{1}{3} \mathbf{I} \otimes \mathbf{I}\right)$

where $K, G, \mathbf{I}$, and $\mathrm{I}^{s}$ are respectively bulk modulus, shear modulus, second order unit tensor, and fourth order symmetric unit tensor. $K$ and $G$ are related with elastic modulus and Poisson's ratio.

According to the experimental results in Fig. 2a, the elastic responses of SPDed grains and RGs are assumed to be identical. The two microstructures differ only through the yield strength and hardening property. For metal, the plastic deformation is determined by the stress deviator:

$\mathbf{s}=\sigma-\frac{1}{3} \operatorname{tr}(\sigma) \mathbf{I}$ 


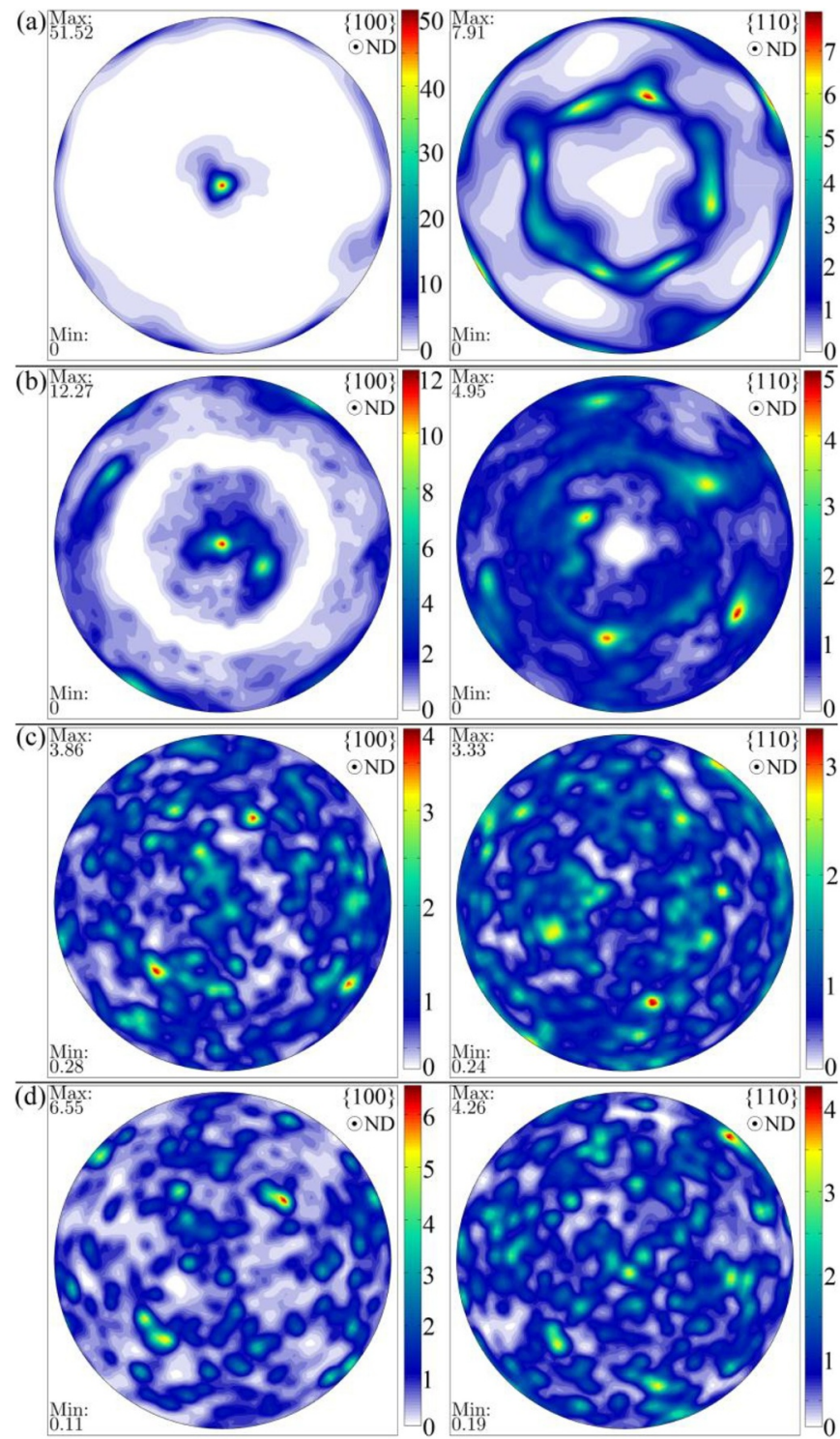

Fig. 7. The pole figures of processed copper at different HT temperatures: (a) HT at $293 \mathrm{~K}$; (b) HT at $523 \mathrm{~K}$; (c) HT at $573 \mathrm{~K}$; (d) HT at $773 \mathrm{~K}$.

where $\operatorname{tr}(\boldsymbol{\sigma})$ is the trace of Cauchy stress tensor $\boldsymbol{\sigma}$. The plastic responses for SPDed grains and RGs are characterized by the following $J_{2}$ criterions:

$$
\left\{\begin{array}{l}
\sqrt{3 J_{2}^{S}}-\left[\sigma_{0}^{S}+\sigma_{1}^{S} V+H_{0}^{S}\left(\varepsilon_{p}^{S}\right)^{n_{0}^{S}}+H_{1}^{S}\left(\varepsilon_{p}^{S}\right)^{n_{1}^{S}} V\right] \leq 0 \\
\sqrt{3 J_{2}^{R}}-\left[\sigma_{0}^{R}+\sigma_{1}^{R}(1-V)+H_{0}^{R}\left(\varepsilon_{p}^{R}\right)^{n_{0}^{R}}+H_{1}^{R}\left(\varepsilon_{p}^{R}\right)^{n_{1}^{R}}(1-V)\right] \leq 0
\end{array}\right.
$$

with SPDed grain and RG labeled by superscript $S$ and $\mathrm{R}$ respectively. In Eq. (11), $V(0 \leq V \leq 1)$ is the volume fraction of recrystallization. The elastic domains of SPDed grains and RGs are bounded by Eq. (11). The equivalent stresses in SPDed and recrystallized material are defined by:

$\left\{\begin{array}{l}\sigma^{S}=\sqrt{3 J_{2}^{S}}=\sqrt{\frac{3}{2} \mathbf{s}^{S}: \mathbf{s}^{S}} \\ \sigma^{R}=\sqrt{3 J_{2}^{R}}=\sqrt{\frac{3}{2} \mathbf{s}^{R}: \mathbf{s}^{R}}\end{array}\right.$

$\varepsilon_{p}^{S}$ and $\varepsilon_{p}^{R}$ are equivalent plastic strain in SPDed and recrystallized material respectively, which can be calculated by the following form:

$\left\{\begin{array}{l}\varepsilon_{p}^{S}=\sqrt{\frac{2}{3} \mathbf{e}^{S}: \mathbf{e}^{S}} \\ \varepsilon_{p}^{R}=\sqrt{\frac{2}{3} \mathbf{e}^{R}: \mathbf{e}^{R}}\end{array}\right.$

where $\mathrm{e}^{S}$ and $\mathrm{e}^{R}$ are the strain deviator of SPDed and recrystallized material respectively. They are defined by:

$\left\{\begin{array}{l}\mathbf{e}^{S}=\boldsymbol{\varepsilon}^{S}-\frac{1}{3} \operatorname{tr}\left(\boldsymbol{\varepsilon}^{S}\right) \mathbf{I} \\ \mathbf{e}^{R}=\boldsymbol{\varepsilon}^{R}-\frac{1}{3} \operatorname{tr}\left(\boldsymbol{\varepsilon}^{R}\right) \mathbf{I}\end{array}\right.$

where $\varepsilon^{S}$ and $\varepsilon^{R}$ are plastic strain tensor of SPDed and recrystallized material respectively. In Eq. (11), $\sigma_{0}^{S}$ and $\sigma_{0}^{R}$ are the yield strength of single-microstructural SPDed material and recrystallized material respectively. They can be determined from the experimental measurements in Fig. 2a. $H_{0}^{S}$ is the strain hardening modulus of SPDed material. $n_{0}^{S}$ is the hardening exponent of SPDed material. $H_{0}^{R}$ and $n_{0}^{R}$ are respectively the strain hardening modulus and exponent of recrystallized material. Due to the mechanical incompatibility (Ovid'ko et al., 2018), the recrystallized material and SPDed material affect the strength and ductility of each other. The term $\left(\sigma_{1}^{S}+H_{1}^{S}\left(\varepsilon_{p}^{S}\right)^{n_{1}^{S}}\right) V$ and $\left(\sigma_{1}^{R}+H_{1}^{R}\left(\varepsilon_{p}^{R}\right)^{n_{1}^{R}}\right)(1-V)$ in Eq. (11) are the effect of hierarchical-microstructure on the mechanical property of SPDed and recrystallized material respectively. For $V=0$, there is no RG in SPDed copper. Eq. (11) becomes the following form:

$\sqrt{3 J_{2}^{S}}-\left[\sigma_{0}^{S}+H_{0}^{S}\left(\varepsilon_{p}^{S}\right)^{n_{0}^{S}}\right] \leq 0$

which is the same as the conventional plastic model of SPDed material. As for $V=1$, completed recrystallization happens in SPDed copper.

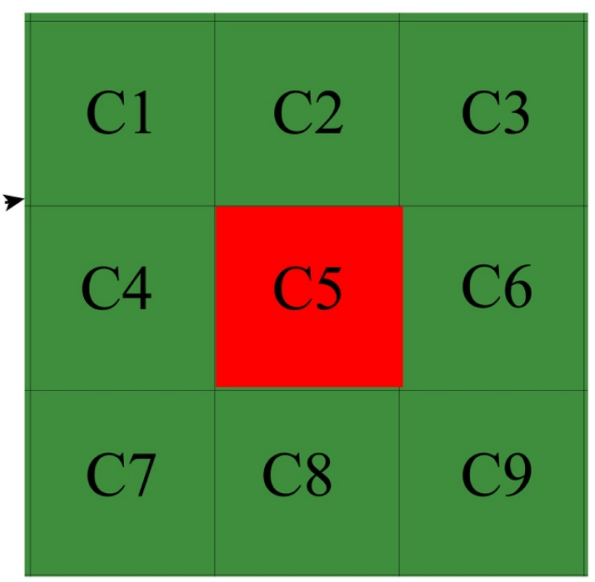

Fig. 8. 2-D Moore configuration with both nearest (C2, C4, C6 and C8) and next-nearest (C1, C3, C7 and C9) neighbors. 


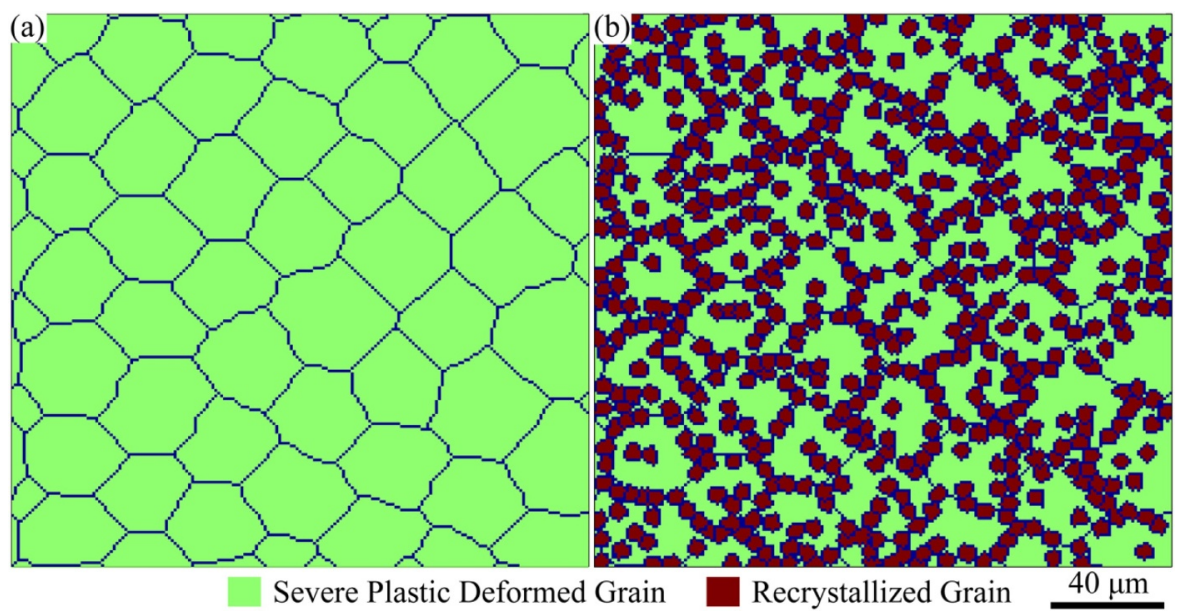

Fig. 9. (a) Simulated microstructure of copper sheet according to cellular automaton (CA); (b) Simulated recrystallization in severe plastic deformed copper sheet.

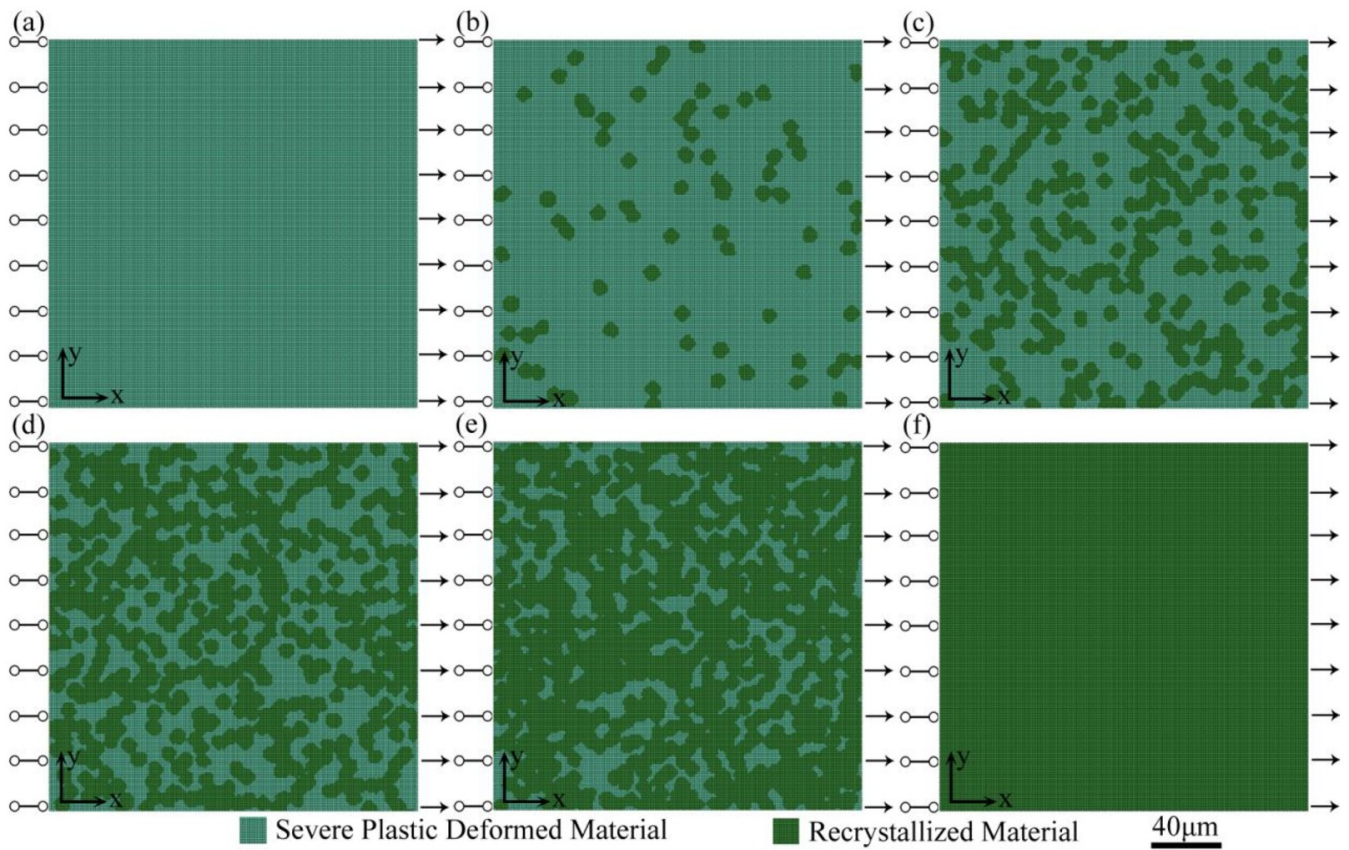

Fig. 10. Finite element models (FEMs) with different volume fractions of recrystallization: (a) $0 \%$; (b) 11\%; (c) 37\%; (d) 57\%; (e) 76\%; (f) 100\%.

Table 1

Material parameters for theoretical model.

\begin{tabular}{lll}
\hline Property & Value & Source \\
\hline$G$ & $42.1 \mathrm{GPa}$ & Literature from Frost and Ashby (1982) \\
$E$ & $117 \mathrm{GPa}$ & Idem \\
$b$ & $0.256 \mathrm{~nm}$ & Idem \\
$k_{1}$ & $8.5 \times 10^{7} \mathrm{~m}^{-1}$ & Literature from Ding and Guo (2001) \\
$k_{2}$ & $5.7 \times 10^{-4}$ & Idem \\
$\alpha$ & 0.5 & Idem \\
$\sigma_{0}^{S}$ & $450 \mathrm{MPa}$ & Data fitting from Mishra et al. (2007) and \\
& & Wang et al. (2002) \\
$H_{0}^{S}$ & $50 \mathrm{MPa}$ & Idem \\
$n_{0}^{S}$ & 0.6 & Idem \\
$\sigma_{0}^{R}$ & $50 \mathrm{MPa}$ & Idem \\
$H_{0}^{R}$ & $360 \mathrm{MPa}$ & Idem \\
$n_{0}^{R}$ & 0.6 & Idem \\
$\rho^{R}$ & $8 \times 10^{13} \mathrm{~m}^{-2}$ & Literature from Liu et al. (2019) \\
$\rho^{S}$ & $1 \times 10^{15} \mathrm{~m}^{-2}$ & Idem \\
$l$ & $370 \mathrm{~nm}$ & Experimental measurement in Fig. 5 \\
$d$ & $4 \mu \mathrm{m}$ & Idem
\end{tabular}

There is no SPDed grain in copper; therefore, Eq. (11) degrades into the conventional plastic model of recrystallized material:

$\sqrt{3 J_{2}^{R}}-\left[\sigma_{0}^{R}+H_{0}^{R}\left(\varepsilon_{p}^{R}\right)^{n_{0}^{R}}\right] \leq 0$

Because of the mechanical incompatibility (Ovid'ko et al., 2018), the strength and strain hardening rate of RG core are related with the surrounding subgrains, which are suggested by:

$\sigma_{1}^{R}=\frac{2 E b}{l}$

$H_{1}^{R}=-\alpha G b \frac{1}{2 \sqrt{\rho^{S}}}\left(\frac{1}{b d}+k_{1} \sqrt{\rho^{S}}-k_{2} \rho^{S}\right)$

In Eq. (17), $E$ is elastic modulus, $b$ is magnitude of Burger's vector and $l$ is the average spacing of cell-block boundary (CBB) (Hamelin et al., 2011). Eq. (18) is derived by combining KocksMecking-Estrin (KME) (Estrin and Mecking, 1984; Mecking and Kocks, 1981) model and Taylor equation (Taylor, 1934, 1938). In Eq. (18), $\alpha$ is a dislocation interaction term, $\rho^{S}$ is the dislocation in 


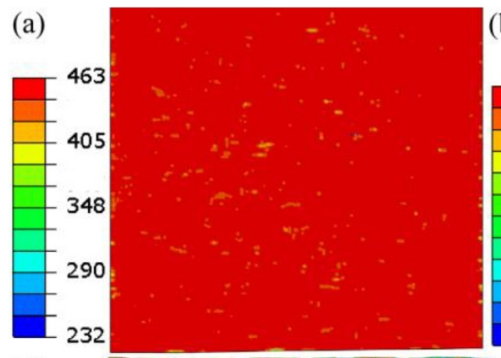

(d)

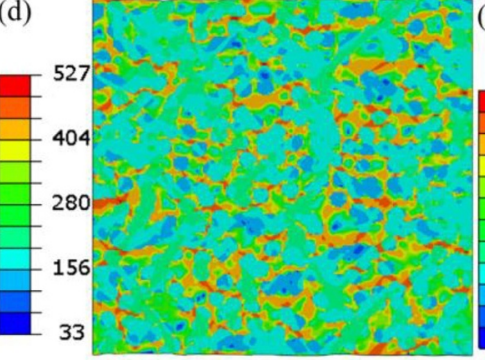

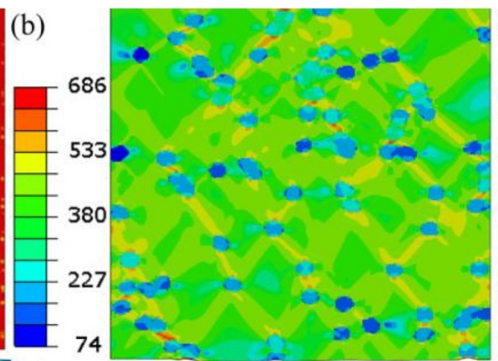

(e)
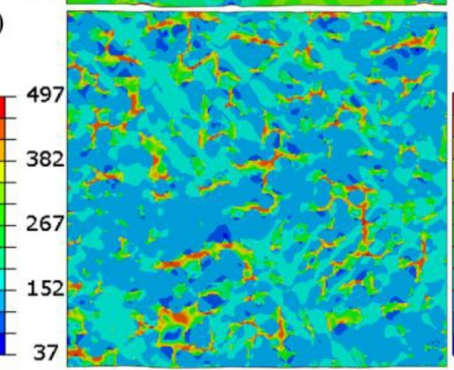
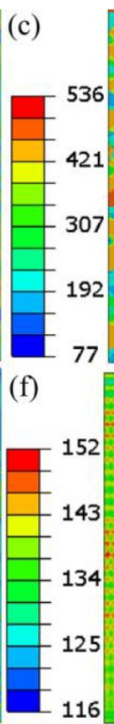
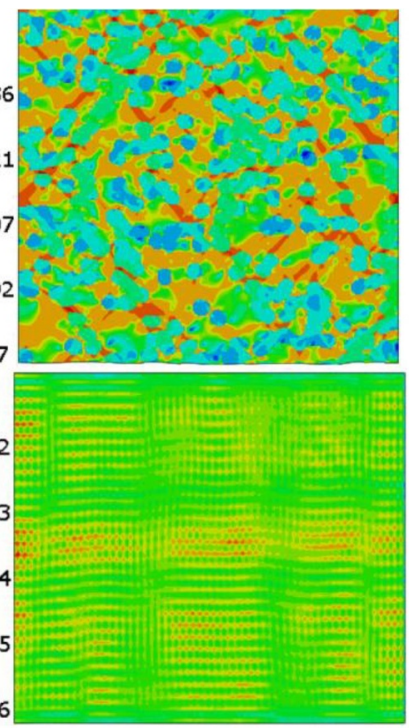

Fig. 11. Equivalent stress distributions at different volume fractions of recrystallization: (a) $0 \%$; (b) 11\%; (c) 37\%; (d) 57\%; (e) 76\%; (f) 100\%.
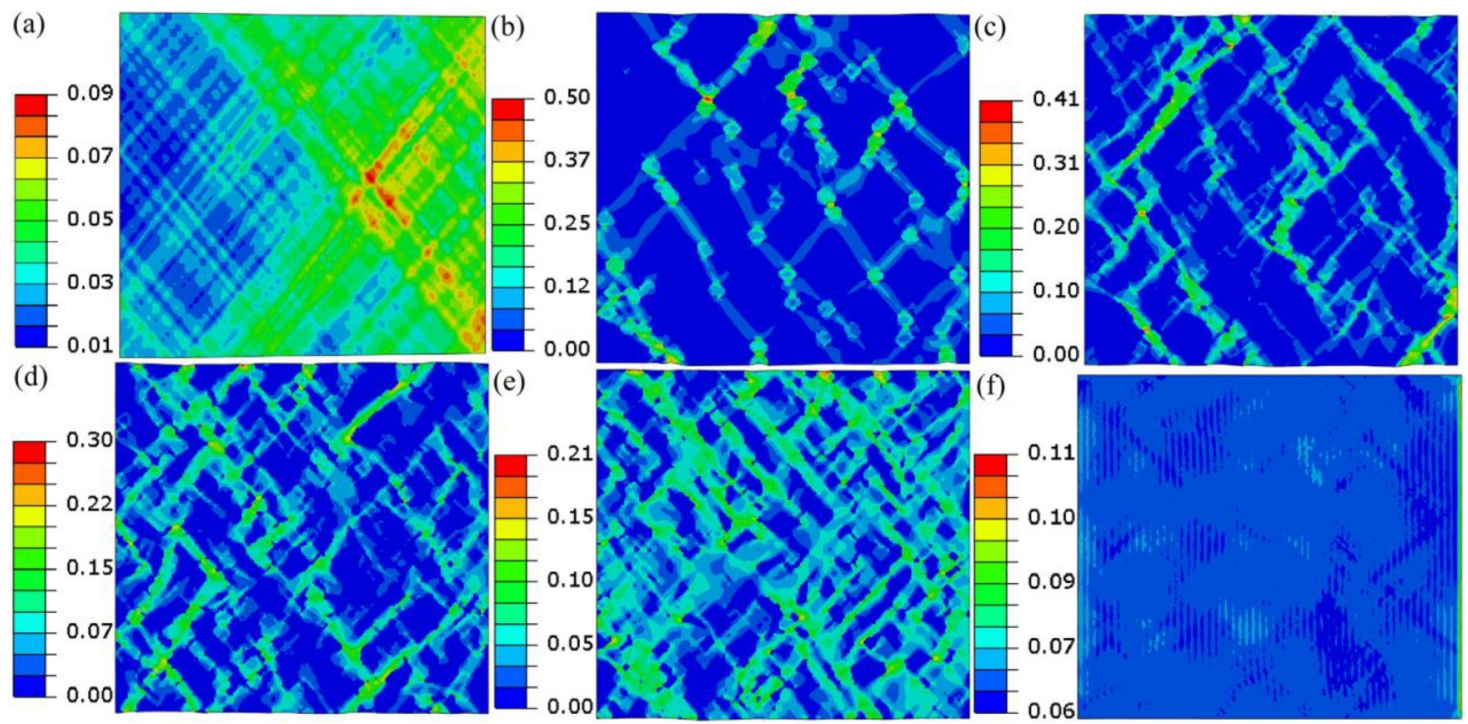

Fig. 12. Equivalent plastic strain distributions at different volume fractions of recrystallization: (a) $0 \%$; (b) $11 \%$; (c) $37 \%$; (d) $57 \%$; (e) $76 \%$; (f) $100 \%$.

(a)

(b)

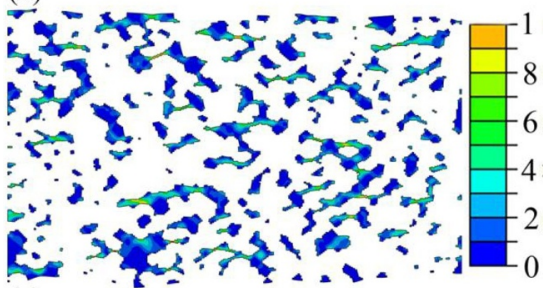

(c)
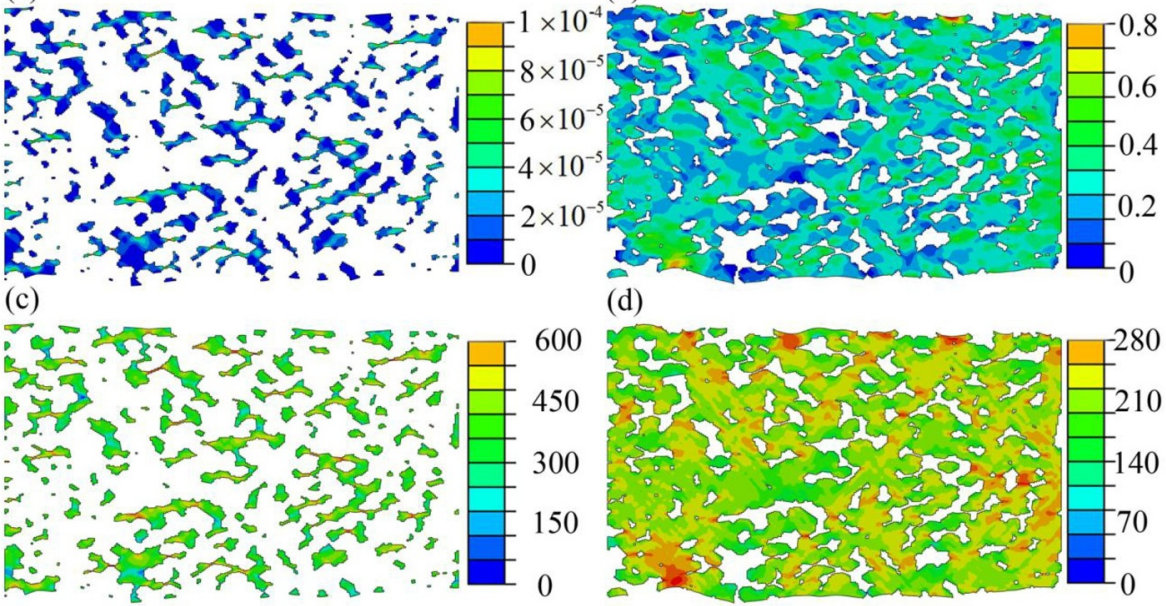

(d)

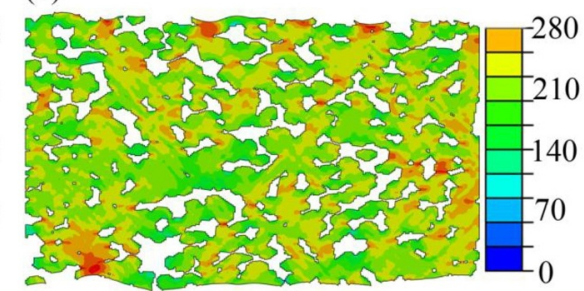

Fig. 13. Plastic strain and stress distributions of $76 \%$ recrystallized copper at the engineering strain of 30\%: (a) Plastic strain distribution in SPDed material; (b) Plastic strain distribution in recrystallized material; (c) Stress distribution in SPDed material; (d) Stress distribution in recrystallized material. 

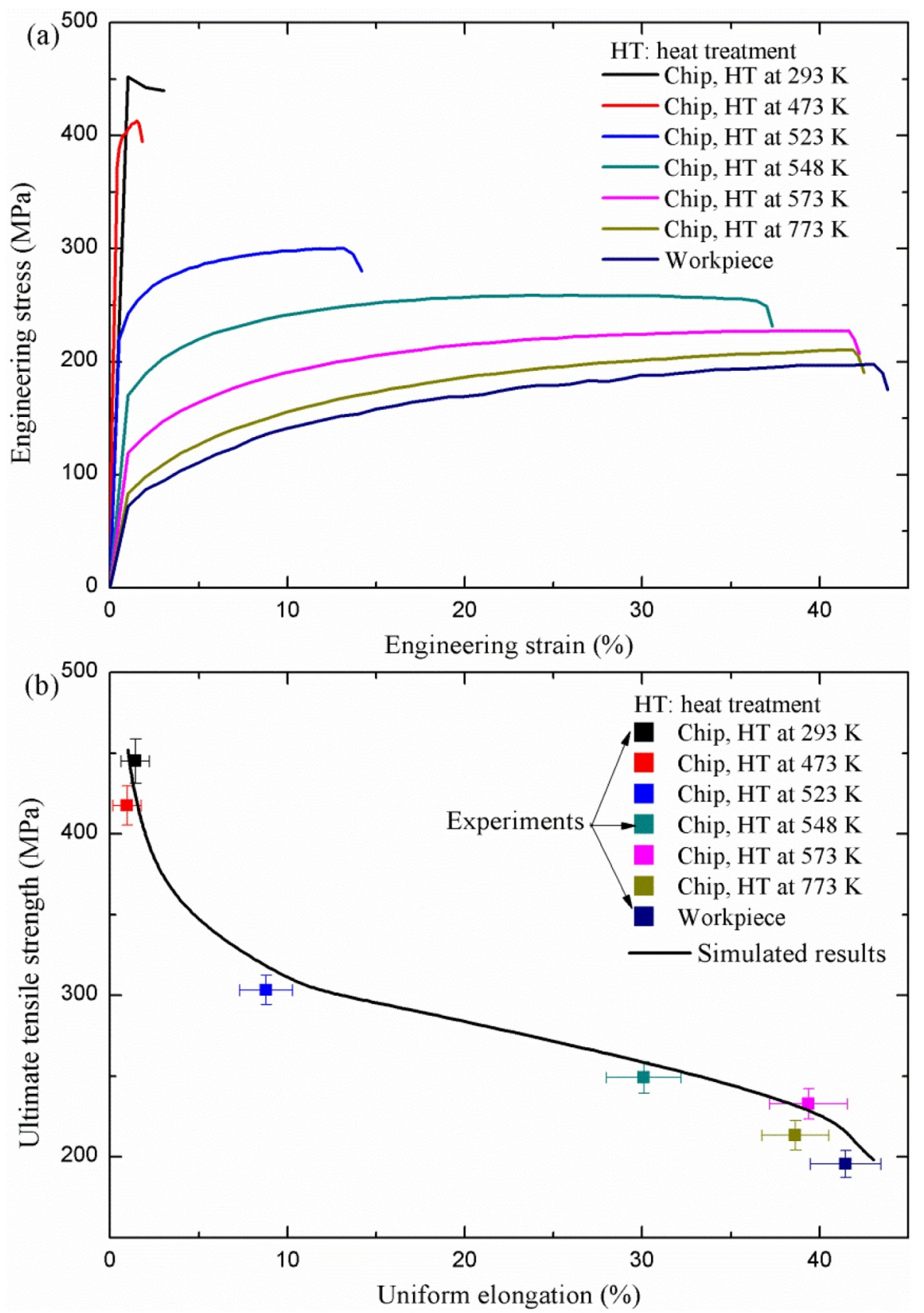

Fig. 14. (a) Simulated engineering stress-strain curves at different HT temperatures; (b) Comparisons of ultimate tensile strength and uniform elongation between FEM and experiments.

SPDed grains, $d$ is the average grain size of RG, $k_{1}$ is dislocation storage rate, and $k_{2}$ is dynamic recovery rate. Eq. (18) is negative, which means that the mechanical incompatibility between SPDed grain and RG results in the decreasing strain hardening rate in RG.

The effect of RG core on the surrounding subgrains is given by the same forms:

$\sigma_{1}^{S}=-\frac{2 E b}{d}$

$H_{1}^{S}=\alpha G b \frac{1}{2 \sqrt{\rho^{R}}}\left(\frac{1}{b d}+k_{1} \sqrt{\rho^{R}}-k_{2} \rho^{R}\right)$

The negative Eq. (19) indicates that the mechanical incompatibility between SPDed grains and RG leads to the decrease of strength in SPDed grains. $\rho^{R}$ in Eq. (20) is the dislocation density in RG.

Because partial recrystallized copper is composed of SPDed grains and RGs, it is required to introduce an interface into the proposed FEM. On the interface $A$ between SPDed material and recrystallized material, it is necessary to have:

$\left.\mathbf{u}^{S}\right|_{A}=\left.\mathbf{u}^{R}\right|_{A}$

where $\mathbf{u}^{S}$ and $\mathbf{u}^{R}$ are respectively the displacement vector of SPDed and recrystallized material.

\section{Numerical result and discussion}

Based on the proposed theory, a user material subroutine was established into ABAQUS to predict the mechanical behavior of partial recrystallized copper. FEMs for different volume fraction of recrystallization have been set up in Fig. 10; however, the material parameters in Eq. (11) are needed to simulate the tensile deformation. The experimental data of SPDed copper and annealed copper 

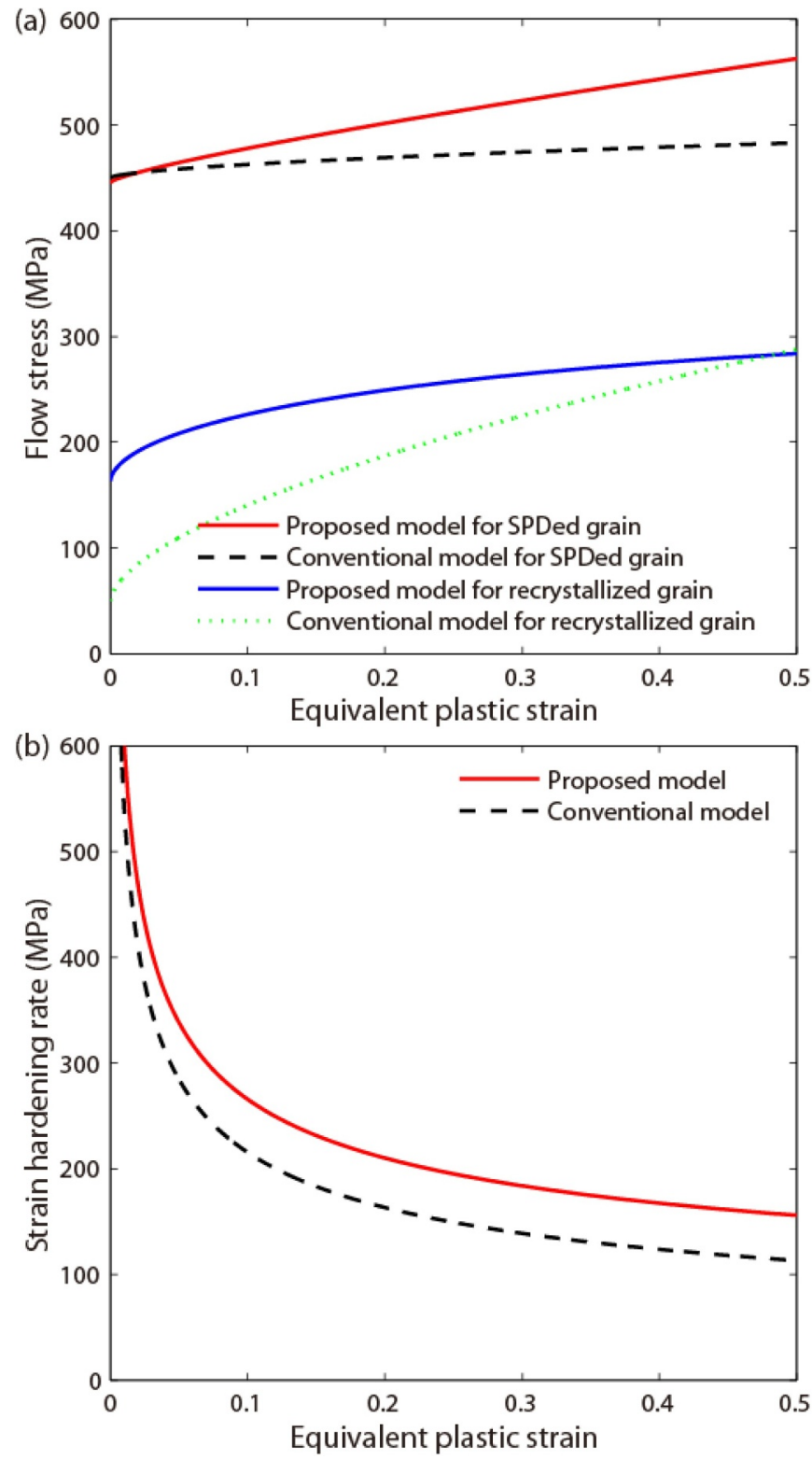

Fig. 15. (a) Comparison of flow stress between hierarchical-microstructure based model and conventional model; (b) Comparisons of strain hardening rate between hierarchical-microstructure based model and conventional model.

(Mishra et al., 2007; Wang et al., 2002) were employed to determine the corresponding material parameters. The detailed derivations of the parameter values in plasticity model are demonstrated in Appendix A. The elastic deformations for all microstructures in partial recrystallized copper are assumed to be the same. The values are achieved from experimental measurements (Li et al., 2008a; Tian et al., 2018). The material parameters for hierarchical-microstructures are obtained from the measurements in Figs. 3-7. The detailed material parameters for the simulations are provided in Table 1.

\subsection{Validation of numerical results}

Fig. 11 shows equivalent stress distributions at the same engineering strain of $1.5 \%$. For single microstructure material, the equivalent stress distribution is homogeneous (Fig. 11a and f). Compared with the completed recrystallized material (Fig. 11f), the equivalent stress is larger in the SPDed material (Fig. 11a). As for hierarchical-microstructure material, the inhomogeneous deformation emerges in material (Fig. 11b-e). Combining Figs. 10 and 11, the equivalent stress in SPDed grains is larger than that in RGs during the process of tensile deformation. The difference of equivalent stress between SPDed grains and RGs becomes smaller at larger volume fraction of recrystallization. As shown in Fig. 11, the maximum of equivalent stress decreases with the increasing volume fraction of recrystallization. This explains the decrease of ultimate tensile strength in experimental measurements (Fig. 2b).

The equivalent plastic strain distributions are visualized in Fig. 12 at the corresponding moment of Fig. 11. For SPDed material in Fig. 12a, the largest plastic strain locates at $\sim 45^{\circ}$ angle where deformation localization happens. The phenomenon explains the small uniform elongation for SPDed material observed in Fig. 2. Compared with plastic strain field in Fig. 12a, the plastic strain distribution in Fig. 12f is more homogeneous. It is found that completed recrystallization helps to improve the ductility of material. As for equivalent plastic strain distribution in hierarchical-microstructure material, the plastic strain is larger in RGs than that in SPDed grains (Fig. 12b-e). The larger deformation zones in Fig. 12b-e are interconnected under $\sim \pm 45^{\circ}$ angle, which contributes to the suppression of deformation localization. It is illustrated in Fig. 12b-e that the density of interconnection increases with the increasing volume fraction of recrystallization. This explains the increase of uniform elongation with recrystallization volume fraction in experiments (Fig. 2b).

For partial recrystallized copper, the mechanical responses of SPDed material and recrystallized material are separated to analyze their effect to the strength and ductility of partial recrystallized copper. Fig. 13 shows the plastic strain and stress distributions of $76 \%$ recrystallized copper at the engineering strain of $30 \%$. According to Fig. 13a-b, the plastic strain level in SPDed material is far less than that in recrystallized material. As illustrated in Fig. 13c-d, the average stress in SPDed material is larger than that in recrystallized material. The combination of SPDed material and recrystallized material can simultaneously improve the strength and ductility. This explains the improvement of strength without losing the ductility in partial crystallized copper (Fig. 2a). Meanwhile, it is found from Fig. 13a-b that most of the plastic strain in partial recrystallized copper can be shared by recrystallized material. The average level of plastic strain in SPDed material is $\sim 5 \times 10^{-5}$ although the strain level in $76 \%$ recrystallized copper is $30 \%$. The plastic strain level in SPDed material is still within the plastic strain range over which the data (Fig. A) were fitted to determine material parameter; thus, it is reasonable to use the parameters of SPDed material within a low plastic strain range for simulating the large deformation behavior of partial recrystallized copper.

The stress-strain responses were further calculated to validate the rationality of the present model. Fig. 14a shows the simulated stressstrain responses of partial recrystallized copper during tensile deformation. SPDed copper annealed at low temperature possesses high strength but poor uniform elongation. Both the yield strength and ultimate tensile strength decrease with the increasing HT temperature. The uniform elongation is larger for higher HT temperature. The predicted stress-strain curves (Fig. 14a) are in good accordance with the experimental results in Fig. 2a. The comparisons of ultimate tensile strength and uniform elongation between FEM and experiments are also presented in Fig. 14b. According to Fig. 14b, the experimental measurements validate the rationality of FEM simulation. Therefore, the proposed model is capable of predicting the mechanical behavior of partial recrystallized copper.

\subsection{Comparison of two plasticity models}

To understand the proposed model comprehensively, the differences between hierarchical-microstructure based model and conventional model are discussed in this section. Eq. (11) describe the flow stress in the frame of hierarchical-microstructure based plasticity model. The 

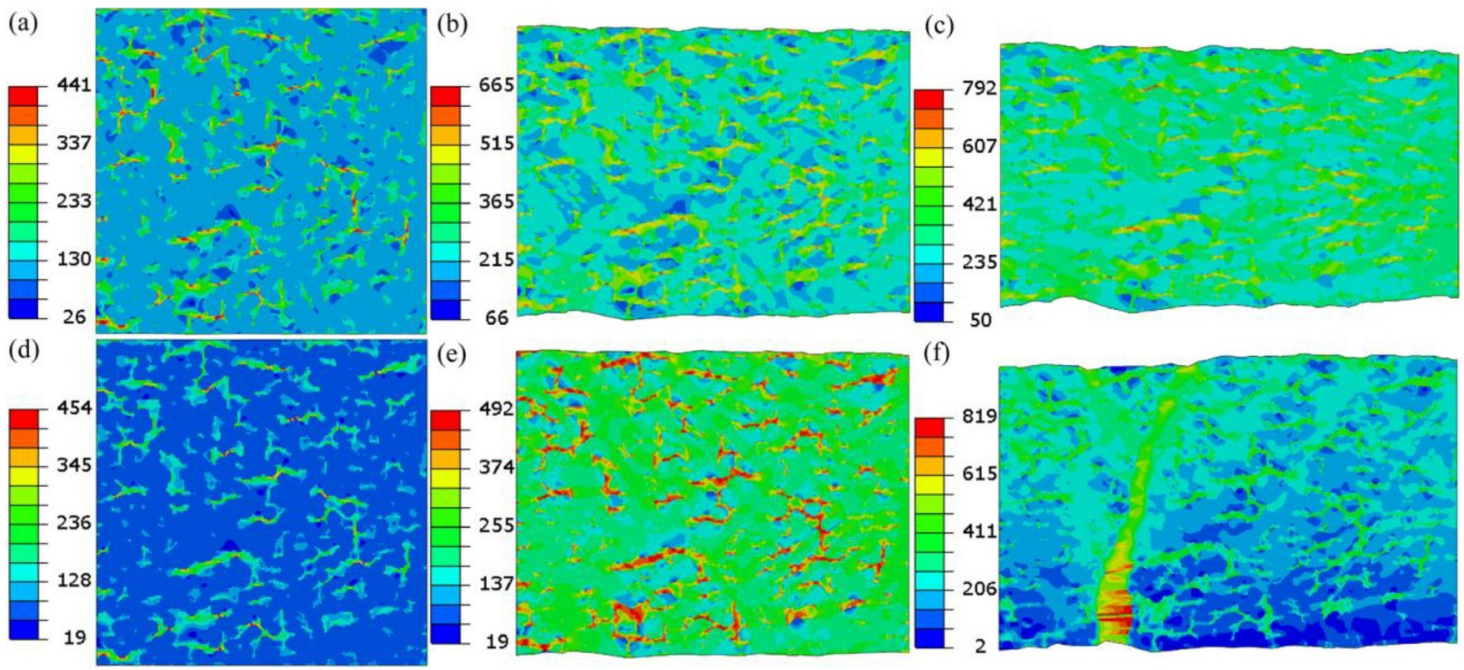

Fig. 16. Equivalent stress distributions of hierarchical-microstructure based FEM model at different engineering strains: (a) 1\%; (b) 16\%; (c) $32 \%$. Equivalent stress distributions of conventional FEM model at different engineering strains: (d) $1 \%$; (e) 16\%; (f) $32 \%$.
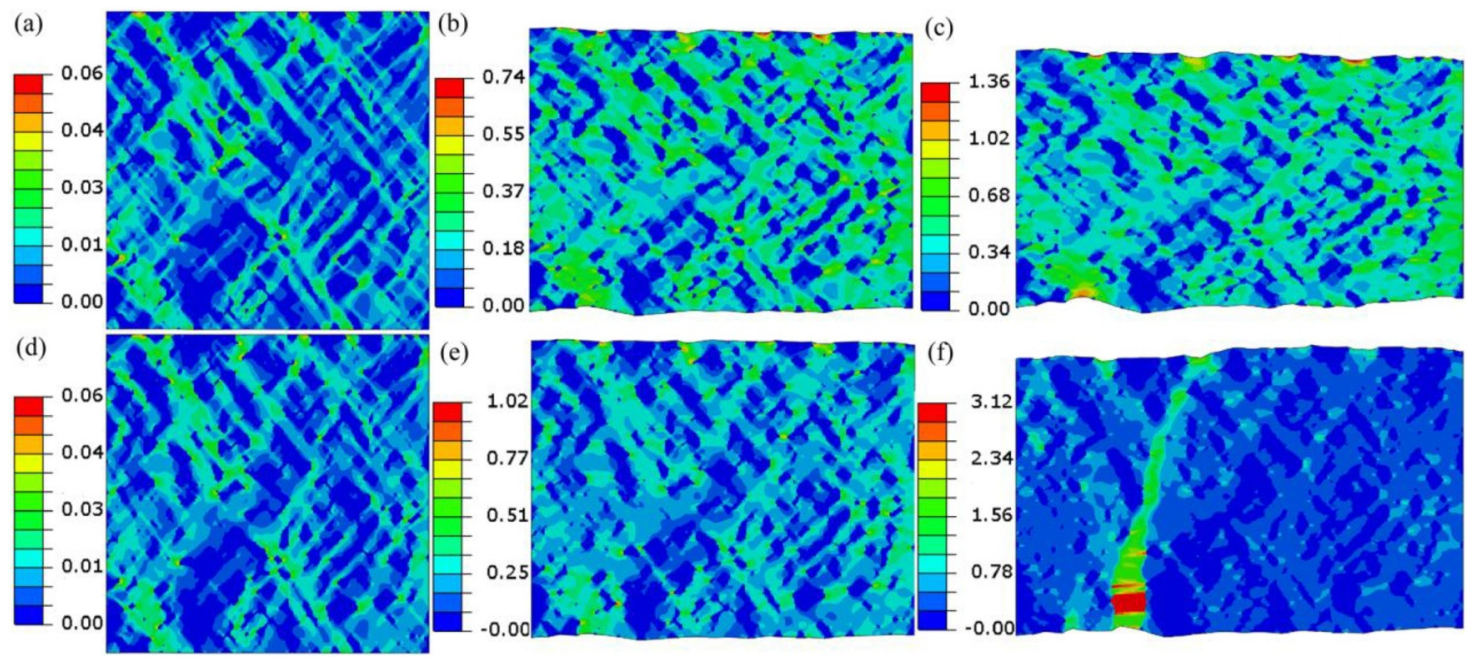

Fig. 17. Equivalent plastic strain distributions of hierarchical-microstructure based FEM model at different engineering strains: (a) 1\%; (b) 16\%; (c) 32\%. Equivalent plastic strain distributions of conventional FEM model at different engineering strains: (d) 1\%; (e) 16\%; (f) $32 \%$.

terms $\left(\sigma_{1}^{S}+H_{1}^{S}\left(\varepsilon_{p}^{S}\right)^{n_{1}^{S}}\right) V$ and $\left(\sigma_{1}^{R}+H_{1}^{R}\left(\varepsilon_{p}^{R}\right)^{n_{1}^{R}}\right)(1-V)$ in Eq. (11) characterize the effect of hierarchical-microstructure on the mechanical property of SPDed and recrystallized material respectively. As for conventional plasticity model, the effects of hierarchical-microstructure on the mechanical properties are not taken into consideration. Therefore, the conventional plasticity model is given by:

$\left\{\begin{array}{l}\sqrt{3 J_{2}^{S}}-\left[\sigma_{0}^{S}+H_{0}^{S}\left(\varepsilon_{p}^{S}\right)^{n_{0}^{S}}\right] \leq 0 \\ \sqrt{3 J_{2}^{R}}-\left[\sigma_{0}^{R}+H_{0}^{R}\left(\varepsilon_{p}^{R}\right)^{n_{0}^{R}}\right] \leq 0\end{array}\right.$

where SPDed grain and RG are respectively labeled by superscript $S$ and R.

As shown in Eqs. (11) and (22), the material parameters in conventional plasticity model are one part of the material parameters in hierarchical-microstructure based model. Substituting the material parameters in Table 1 into Eqs. (11) and (22), the flow stresses and strain hardening rates for different plasticity models are obtained. Fig. 15 shows the comparisons between hierarchical-microstructure based model and conventional model in the case of 30\% recrystallization volume fraction. For both SPDed grain and recrystallized grain, flow stress predicted by hierarchical-microstructure based model is larger than that predicted by conventional model. For recrystallized grain, the deviation of flow stress prediction between hierarchical-microstructure based model and conventional model decreases with the increasing equivalent plastic strain; however, the deviation for SPDed grain increases with the increasing equivalent plastic strain. As shown in Fig. 15b, the strain hardening rate in hierarchical-microstructure based model is larger than that in conventional model. Comparing Eqs. (11) and (22), the strengthening mechanism from hierarchical microstructure is not taken into consideration in conventional model. This explains the low flow stress and low strain hardening rate predicted by conventional model. The neglect of the strengthening mechanism from hierarchical microstructure indicates that the stressstrain response predicted by conventional model could deviate from the experimental results of Fig. 2.

Figs. 16 and 17 show respectively the equivalent stress distribution and the equivalent plastic strain distribution for the recrystallization volume fraction of $76 \%$. Compared Fig. 16a-b with d-e, the stress distribution of hierarchical-microstructure based model is similar to that of conventional model for early and middle stage of tensile deformation. If engineering strain is less than $16 \%$, plastic strain distributions simulated by hierarchical-microstructure based model are similar to 

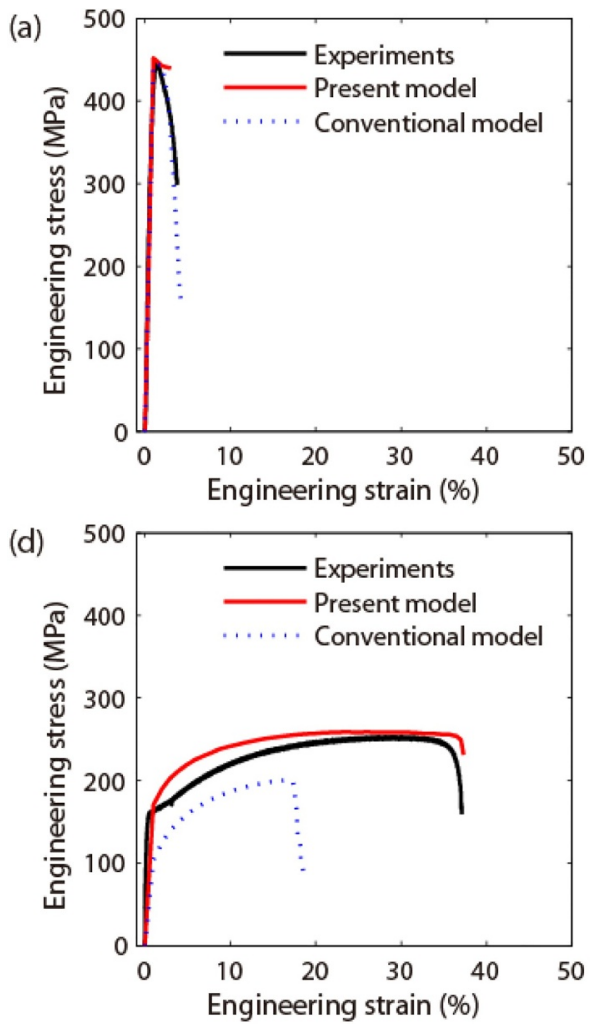
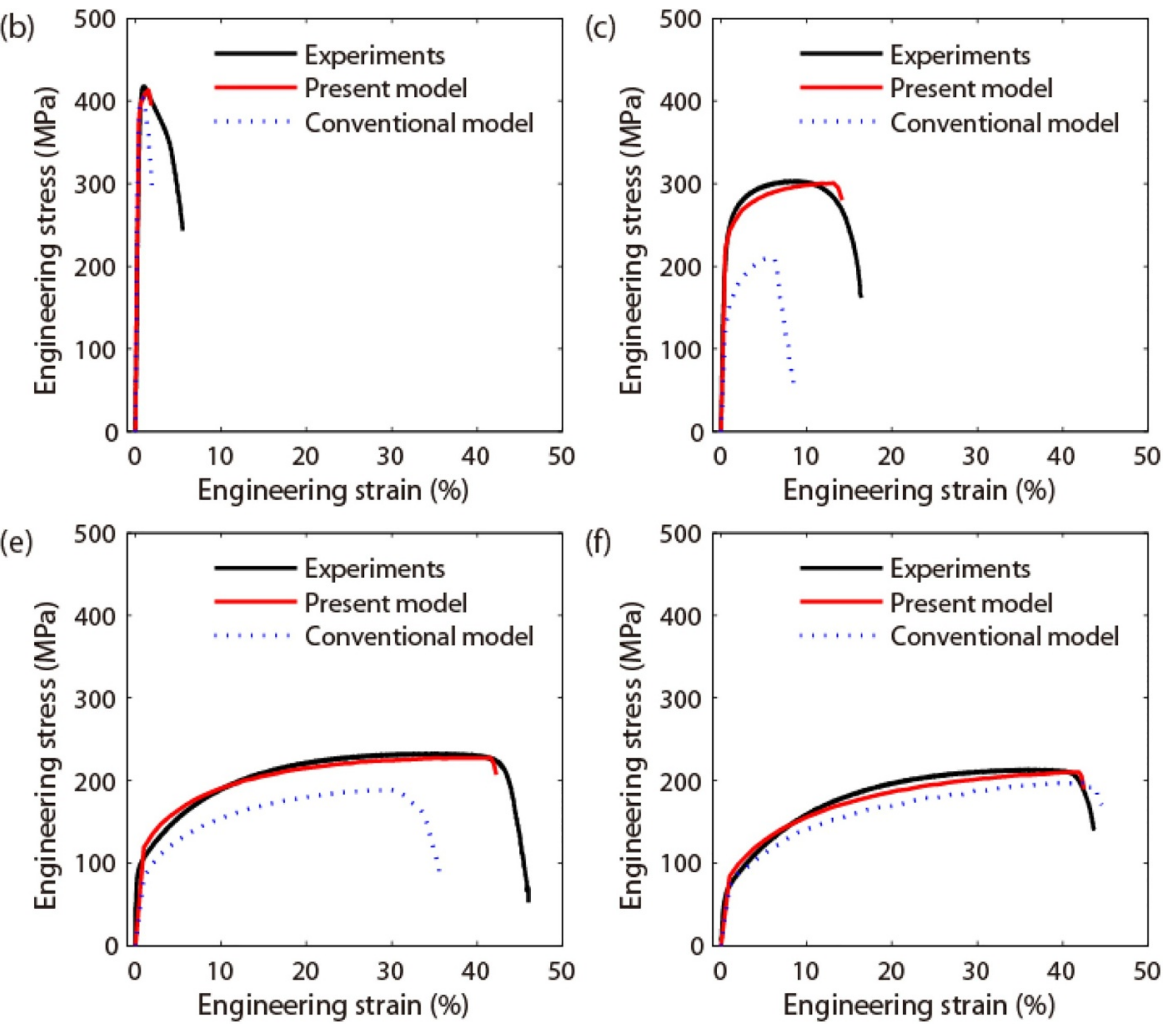

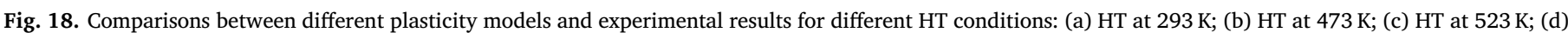
HT at $548 \mathrm{~K}$; (e) HT at $573 \mathrm{~K}$; (f) HT at $773 \mathrm{~K}$.

those simulated by conventional model (Fig. 17a-b and d-e). When engineering strain exceeds a certain value, i.e. $32 \%$ in this FEM, stress concentration and deformation localization happen in conventional plastic model (Figs. 16f and 17f). Deformation localization indicates that the material lose the load carrying and energy absorption capacity (Dodd and Bai, 2012; Meyers and Chawla, 2009). However, at the identical engineering strain, there is no stress concentration or deformation localization in hierarchical-microstructure based plastic model (Figs. 16c and 17c).

The comparison of the two models with experiments is further illustrated in Fig. 18. For only one type of grain, i.e., full severe plastic deformed (SPDed) grain (Fig. 18a) or full recrystallized grain (Fig. 18f), both the present model and the conventional model can capture well the experimental results. According to the proposed theory, the present model can degrade into the conventional model when recrystallization fraction is $0 \%$ or $100 \%$. This explains the results in Fig. 18a and $\mathrm{f}$. When volume fraction of recrystallization is less than $50 \%$, the difference between conventional model and experiments becomes larger with the increasing volume fraction of recrystallization. However, when volume fraction of recrystallization is larger than $50 \%$, the difference between conventional model and experiments becomes smaller with the increasing volume fraction of recrystallization. As shown in Fig. 18, the equivalent stress of hierarchical-microstructure based plasticity model is higher than that of conventional plasticity model. The uniform elongation of conventional plasticity model is less than that of hierarchical-microstructure based plasticity model. Compared with the conventional plasticity model, the stress-strain response predicted by hierarchical-microstructure based plasticity model is in better agreement with the corresponding experiment. This is to say hierarchicalmicrostructure based plasticity model is more effective than conventional plasticity model to characterize the mechanical response of partial recrystallized copper.

\section{Conclusions}

A SPD method of quasi-static extrusion machining (QSEM) was used to produce SPDed copper. Then, a systematic heat treatment (HT) at six annealing temperatures was conducted on SPDed copper to obtain partial recrystallized copper with different volume fraction of recrystallization. The microstructure and mechanical property of partial recrystallized copper were investigated in this study. The following conclusions can be drawn.

(1) Uniaxial tensile tests reveal that uniform elongation of partial recrystallized copper increases but its ultimate tensile strength decreases with the increasing HT temperature.

(2) Microstructural observations show that a hierarchical-microstructure of recrystallized grains (RGs) surrounded by elongated subgrains affects the mechanical properties of partial recrystallized cooper and the volume fraction of RG increases with the increasing HT temperature.

(3) A hierarchical-microstructure based plasticity model is proposed to predict the mechanical behavior of partial recrystallized copper, where elongated subgrain, RG, forest dislocation, low angle grain boundary (LAGB) and twin boundary (TB) are taken into consideration.

(4) Compared with the conventional plasticity model, the stress-strain response predicted by hierarchical-microstructure based plasticity model is in better agreement with the corresponding experimental data. Therefore, the present model is valid to predict mechanical properties of partial recrystallized copper.

\section{Declaration of Competing Interest}

None. 


\section{Acknowledgements}

This work has been supported by the National Key Research and Development Program of China (No. 2017YFB0702003), the National Natural Science Foundation of China (Nos. 11602236 and 11802013), Fundamental Research Funds for the Central Universities (No. FRF-TP-
18-020A2), China Scholarship Council, the Strategic Priority Research Program of the Chinese Academy of Sciences (Nos. XDB22040302, XDB22040303) and the Key Research Program of Frontier Sciences (No. QYZDJSSW-JSC011). We are very grateful to the anonymous reviewers for their helpful comments, which have improved this paper significantly.

\section{Supplementary materials}

Supplementary material associated with this article can be found, in the online version, at doi:10.1016/j.mechmat.2019.103207.

\section{Appendix A}

The available experimental data (Mishra et al., 2007; Wang et al., 2002) were used here to obtain the parameter values in plasticity models (11) and (22). The uniaxial tensile data for SPDed copper and RGed copper in references (Mishra et al., 2007; Wang et al., 2002) are illustrated in Fig. A(a). The mean yield strengths for SPDed and RGed copper are directly calculated in Fig. A(a), i.e., $\sigma_{0}^{S} \approx 450 \mathrm{MPa}$ and $\sigma_{0}^{R} \approx 50 \mathrm{MPa}$. The recrystallization volume fraction in SPDed cooper is zero. The recrystallization volume fraction in RGed cooper is $100 \%$. There are no hierarchical microstructures in SPDed and RGed copper. Therefore, the plastic deformation can be controlled by plasticity model ((22), i.e.,
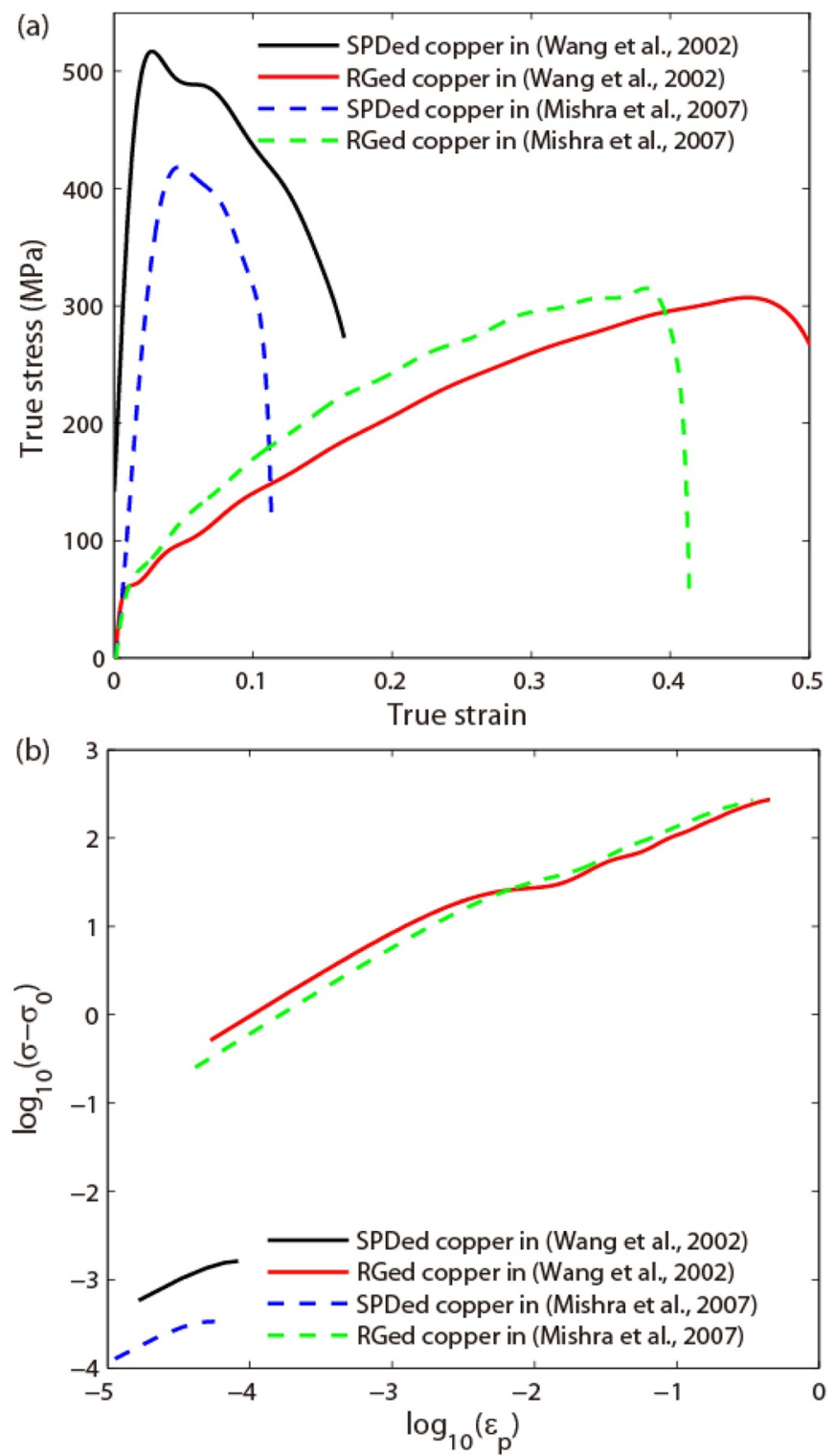

Fig. A. Experimental data from Mishra et al. (2007) and Wang et al. (2002): (a) True stress vs true strain curves for SPDed and RGed copper; (b) Relationships between $\log _{10}\left(\sigma-\sigma_{0}\right)$ and $\log _{10}\left(\varepsilon_{p}\right)$ for SPDed and RGed copper. 
$\left\{\begin{array}{l}\sigma^{S}=\sigma_{0}^{S}+H_{0}^{S}\left(\varepsilon_{p}^{S}\right)^{n_{0}^{S}} \\ \sigma^{R}=\sigma_{0}^{R}+H_{0}^{R}\left(\varepsilon_{p}^{R}\right)^{n_{0}^{R}}\end{array}\right.$

In Eqs. (A1), SPDed and RGed copper are respectively labeled by superscript S and R. $\sigma$ is equivalent stress during uniaxial tensile tests. Eqs. (A1) could be changed into the following forms:

$\left\{\begin{array}{l}\log _{10}\left(\sigma^{S}-\sigma_{0}^{S}\right)=\log _{10} H_{0}^{S}+n_{0}^{S} \log _{10}\left(\varepsilon_{p}^{S}\right) \\ \log _{10}\left(\sigma^{R}-\sigma_{0}^{R}\right)=\log _{10} H_{0}^{R}+n_{0}^{R} \log _{10}\left(\varepsilon_{p}^{R}\right)\end{array}\right.$

Based on true stress vs true strain curves in Fig. A(a), the relationships between $\log _{10}\left(\sigma-\sigma_{0}\right)$ and $\log _{10}\left(\varepsilon_{p}\right)$ are shown in Fig. A(b). By means of linear fitting of experimental data in Fig. A(b), the slope and intercept of linear fitting equation are calculated. Then, strain hardening modulus $H_{0}$ and hardening exponent $n_{0}$ can be obtained. The calculated average values of plastic parameters are: $H_{0}^{S} \approx 50 \mathrm{MPa}, n_{0}^{S} \approx 0.6, H_{0}^{R} \approx 360 \mathrm{MPa}$, and $n_{0}^{R} \approx 0.6$.

\section{References}

Abdul-Latif, A., Kerkour-El Miad, A., Baleh, R., Garmestani, H., 2018. Modeling the mechanical behavior of heterogeneous ultrafine grained polycrystalline and nanocrystalline FCC metals. Mech. Mater. 126, 1-12.

Altan, B.S., Subhash, G., 2003. A nonlocal formulation based on a novel averaging scheme applicable to nanostructured materials. Mech. Mater. 35, 281-294.

Avrami, M., 1939. Kinetics of phase change. I. J. Chem. Phys. 7, 1103-1112.

Barlat, F., Lege, D.J., Brem, J.C., 1991. A six-component yield function for anisotropic materials. Int. J. Plast. 7, 693-712.

Barlat, F., Vincze, G., Grácio, J.J., Lee, M.G., Rauch, E.F., Tomé, C.N., 2014. Enhancements of homogenous anisotropic hardening model and application to mild and dual-phase steels. Int. J. Plast. 58, 201-218.

Bussemaker, H.J., Deutsch, A., Geigant, E., 1997. Mean-field analysis of a dynamical phase transition in a cellular automaton model for collective motion. Phys. Rev. Lett. 78, 5018-5021.

Chen, F., Cui, Z., Liu, J., Chen, W., Chen, S., 2010. Mesoscal simulation of the hightemperature austenitizing and dynamic recrystallization by coupling a celluar automaton with a topology deformation technique. Mater. Sci. Eng. A 527, 5539-5549.

Chen, F., Cui, Z., Liu, J., Zhang, X., Chen, W., 2009. Modeling and simulation on dynamic recrystallization of $30 \mathrm{Cr}_{2} \mathrm{Ni}_{4} \mathrm{MoV}$ rotor steel using the cellular automation method. Model. Simul. Mater. Sci. Eng. 17, 075015.

Chen, R., Xu, Q., Liu, B., 2015. Cellular automaton simulation of three-dimensional dendrite growth in Al-7Si-Mg ternary aluminum alloys. Comput. Mater. Sci. 105, 90-100.

Christian, J.W., Mahajan, S., 1995. Deformation twinning. Prog. Mater. Sci. 39, 1-157.

Davies, C.H.J., 1997. Growth of nuclei in a cellular automaton simulation of recrystallisation. Scr. Mater. 36, 35-40.

Ding, R., Guo, Z.X., 2001. Coupled quantitative simulation of microstructural evolution and plastic flow during dynamic recrystallization. Acta Mater. 49, 3163-3175.

Dodd, B., Bai, Y., 2012. Adiabatic Shear Localization, (second ed.). Elsevier, Oxford.

El-Tahawy, M., Pereira, P.H.R., Huang, Y., Park, H., Choe, H., Langdon, T.G., Gubicza, J., 2018. Exceptionally high strength and good ductility in an ultrafine-grained $316 \mathrm{~L}$ steel processed by severe plastic deformation and subsequent annealing. Mater. Lett. 214, 240-242.

Estrin, Y., Mecking, H., 1984. A unified phenomenological description of work hardening and creep based on one-parameter models. Acta Metall. 32, 57-70.

Frost, H.J., Ashby, M.F., 1982. Deformation-Mechanism Maps: The Plasticity and Creep of Metals and Ceramics. Pergamon Press, Oxford.

Gandin, C.A., Rappaz, M., 1997. A 3D cellular automaton algorithm for the prediction of dendritic grain growth. Acta Mater. 45, 2187-2195.

Ha, J., Lee, M.-.G., Barlat, F., 2013. Strain hardening response and modeling of EDDQ and DP780 steel sheet under non-linear strain path. Mech. Mater. 64, 11-26.

Hall, E.O., 1951. The deformation and ageing of mild steel: III discussion of results. Proc. Phys. Soc. B 64, 747-753.

Hamelin, C.J., Diak, B.J., Pilkey, A.K., 2011. Multiscale modelling of the induced plastic anisotropy in BCC metals. Int. J. Plast. 27, 1185-1202.

He, Y., Ding, H., Liu, L., Shin, K., 2006. Computer simulation of 2D grain growth using a cellular automata model based on the lowest energy principle. Mater. Sci. Eng. 429, $236-246$.

Hill, R., 1948. A theory of the yielding and plastic flow of anisotropic metals. Proc. R. Soc. Lond. Ser. A. 193, 281-297.

Hooke, R., 1678. De Potentia Restitutiva, or of Spring. Explaining the Power of Springing Bodies. London.

Hori, M., Nemat-Nasser, S., 1999. On two micromechanics theories for determining micro-macro relations in heterogeneous solids. Mech. Mater. 31, 667-682.

Hosford, W.F., 1979. On yield loci of anisotropic cubic metals. In: Proceedings of the. 7th North American Metalworking Conference, pp. 191-197.

Huang, J., Zhang, K.-.M., Jia, Y.-.F., Zhang, C.-.C., Zhang, X.-.C., Ma, X.-.F., Tu, S.-.T., 2019. Effect of thermal annealing on the microstructure, mechanical properties and residual stress relaxation of pure titanium after deep rolling treatment. J. Mater. Sci. Technol. 35, 409-417.

Kühbach, M., Gottstein, G., Barrales-Mora, L.A., 2016. A statistical ensemble cellular automaton microstructure model for primary recrystallization. Acta Mater. 107, 366-376.
Karafillis, A.P., Boyce, M.C., 1993. A general anisotropic yield criterion using bounds and a transformation weighting tensor. J. Mech. Phys. Solids 41, 1859-1886.

Kumar, A., Dutta, A., Makineni, S.K., Herbig, M., Petrov, R.H., Sietsma, J., 2019. In-situ observation of strain partitioning and damage development in continuously cooled carbide-free bainitic steels using micro digital image correlation. Mater. Sci. Eng. 757, 107-116.

Laplanche, G., Kostka, A., Reinhart, C., Hunfeld, J., Eggeler, G., George, E.P., 2017. Reasons for the superior mechanical properties of medium-entropy Crconi compared to high-entropy Crmnfeconi. Acta Mater. 128, 292-303.

Lee, E.H., 1969. Elastic-plastic deformation at finite strains. J. Appl. Mech. 36, 1-6.

Li, W.L., Tao, N.R., Lu, K., 2008a. Fabrication of a gradient nano-micro-structured surface layer on bulk copper by means of a surface mechanical grinding treatment. Scr. Mater. 59, 546-549.

Li, Y.S., Zhang, Y., Tao, N.R., Lu, K., 2008b. Effect of thermal annealing on mechanical properties of a nanostructured copper prepared by means of dynamic plastic deformation. Scr. Mater. 59, 475-478.

Liu, Y., Cai, S., Xu, F., Wang, Y., Dai, L., 2019. Enhancing strength without compromising ductility in copper by combining extrusion machining and heat treatment. J. Mater. Process. Technol. 267, 52-60.

Loret, B., 1983. On the effects of plastic rotation in the finite deformation of anisotropic elastoplastic materials. Mech. Mater. 2, 287-304.

Lu, K., Lu, L., Suresh, S., 2009. Strengthening materials by engineering coherent internal boundaries at the nanoscale. Science 324, 349.

Ma, E., Zhu, T., 2017. Towards strength-ductility synergy through the design of heterogeneous nanostructures in metals. Mater. Today 20, 323-331.

Marx, V., Reher, F.R., Gottstein, G., 1999. Simulation of primary recrystallization using a modified three-dimensional cellular automaton. Acta Mater. 47, 1219-1230.

Mecking, H., Kocks, U.F., 1981. Kinetics of flow and strain-hardening. Acta Metall. 29, 1865-1875.

Meyers, M.A., Chawla, K.K., 2009. Mechanical Behavior of Materials, (second ed.). Cambridge University Press, Cambridge.

Ming, K., Bi, X., Wang, J., 2018. Realizing strength-ductility combination of coarsegrained $\mathrm{Al} 0.2$ Co $1.5 \mathrm{CrFeNi} 1.5 \mathrm{Ti} 0.3$ alloy via nano-sized, coherent precipitates. Int. J. Plast. 100, 177-191.

Mishra, A., Kad, B.K., Gregori, F., Meyers, M.A., 2007. Microstructural evolution in copper subjected to severe plastic deformation: experiments and analysis. Acta Mater. $55,13-28$.

Nemat-Nasser, S., Ni, L., Okinaka, T., 1998. A constitutive model for fcc crystals with application to polycrystalline OFHC copper. Mech. Mater. 30, 325-341.

Osovski, S., Rittel, D., Venkert, A., 2013. The respective influence of microstructural and thermal softening on adiabatic shear localization. Mech. Mater. 56, 11-22.

Ovid'ko, I.A., Valiev, R.Z., Zhu, Y.T., 2018. Review on superior strength and enhanced ductility of metallic nanomaterials. Prog. Mater. Sci. 94, 462-540.

Petch, N.J., 1953. The cleavage strength of polycrystals. J. Iron Steel Inst. 174, 25-28.

Popova, E., Staraselski, Y., Brahme, A., Mishra, R.K., Inal, K., 2015. Coupled crystal plasticity - probabilistic cellular automata approach to model dynamic recrystallization in magnesium alloys. Int. J. Plast. 66, 85-102.

Rittel, D., Landau, P., Venkert, A., 2008. Dynamic recrystallization as a potential cause for adiabatic shear failure. Phys. Rev. Lett. 101, 165501.

Rittel, D., Wang, Z.G., Merzer, M., 2006. Adiabatic shear failure and dynamic stored energy of cold work. Phys. Rev. Lett. 96, 075502.

Sadjadpour, A., Rittel, D., Ravichandran, G., Bhattacharya, K., 2015. A model coupling plasticity and phase transformation with application to dynamic shear deformation of iron. Mech. Mater. 80, 255-263.

Srivastava, A., Nemat-Nasser, S., 2011. Universal theorems for total energy of the dynamics of linearly elastic heterogeneous solids. Mech. Mater. 43, 913-917.

Sun, G., Du, L., Hu, J., Zhang, B., Misra, R.D.K., 2019. On the influence of deformation mechanism during cold and warm rolling on annealing behavior of a 304 stainless steel. Mater. Sci. Eng. 746, 341-355.

Sun, S.J., Tian, Y.Z., An, X.H., Lin, H.R., Wang, J.W., Zhang, Z.F., 2018. Ultrahigh cryogenic strength and exceptional ductility in ultrafine-grained Cocrfemnni highentropy alloy with fully recrystallized structure. Mater. Today Nano 4, 46-53.

Taylor, G.I., 1934. The mechanism of plastic deformation of crystals, Part I-theoretical. Proc. R. Soc. Lond. Ser. A 145, 362-387.

Taylor, G.I., 1938. Plastic strian in metals. J. Inst. Metals 62, 307-325. 
Tian, Y.Z., Gao, S., Zhao, L.J., Lu, S., Pippan, R., Zhang, Z.F., Tsuji, N., 2018. Remarkable transitions of yield behavior and Lüders deformation in pure $\mathrm{Cu}$ by changing grain sizes. Scr Mater 142, 88-91.

Tsagrakis, I., Efremidis, G., Konstantinidis, A., Aifantis, E.C., 2006. Deformation vs. flow and wavelet-based models of gradient plasticity: examples of axial symmetry. Int. J. Plast. 22, 1456-1485.

Valiev, R.Z., Estrin, Y., Horita, Z., Langdon, T.G., Zehetbauer, M.J., Zhu, Y.T., 2016. Fundamentals of superior properties in bulk nanoSPD materials. Mater. Res. Lett. 4, $1-21$.

Varma, A., Krishnaswamy, H., Jain, J., Lee, M.-.G., Barlat, F., 2019. Advanced constitutive model for repeated stress relaxation accounting for transient mobile dislocation density and internal stress. Mech. Mater. 133, 138-153.

Wang, Y., Chen, M., Zhou, F., Ma, E., 2002. High tensile ductility in a nanostructured metal. Nature 419, 912-915.

Wu, S.W., Wang, G., Wang, Q., Jia, Y.D., Yi, J., Zhai, Q.J., Liu, J.B., Sun, B.A., Chu, H.J., Shen, J., Liaw, P.K., Liu, C.T., Zhang, T.Y., 2019. Enhancement of strength-ductility trade-off in a high-entropy alloy through a heterogeneous structure. Acta Mater. 165, 444-458.
Wu, X.L., Yang, M.X., Yuan, F.P., Wu, G.L., Wei, Y.J., Huang, X.X., Zhu, Y.T., 2015. Heterogeneous lamella structure unites ultrafine-grain strength with coarse-grain ductility. Proc. Natl. Acad. Sci. 112, 14501-14505.

Xiao, G.H., Tao, N.R., Lu, K., 2011. Strength-ductility combination of nanostructured $\mathrm{Cu}-\mathrm{Zn}$ alloy with nanotwin bundles. Scr. Mater. 65, 119-122.

Zaiser, M., Aifantis, E.C., 2006. Randomness and slip avalanches in gradient plasticity. Int. J. Plast. 22, 1432-1455.

Zhang, Y., Tao, N.R., Lu, K., 2008. Mechanical properties and rolling behaviors of nanograined copper with embedded nano-twin bundles. Acta Mater. 56, 2429-2440.

Zheng, R., Bhattacharjee, T., Shibata, A., Sasaki, T., Hono, K., Joshi, M., Tsuji, N., 2017. Simultaneously enhanced strength and ductility of $\mathrm{Mg}$-Zn-Zr-Ca alloy with fully recrystallized ultrafine grained structures. Scr. Mater. 131, 1-5.

Ziaei, S., Zikry, M.A., 2019. How semi-coherent b.c.c. hydride interfacial interactions affect the inelastic deformation and fracture behavior of h.c.p. zirconium alloys. Mech. Mater. 130, 1-8.

Zikry, M.A., Kameda, T., 1998. Inelastic three dimensional high strain-rate dislocation density based analysis of grain-boundary effects and failure modes in ordered intermetallics. Mech. Mater. 28, 93-102. 